Chapter 13

\title{
Ecology of Larval Habitats
}

\author{
Eliška Rejmánková, John Grieco, Nicole Achee and \\ Donald R. Roberts
}

Additional information is available at the end of the chapter

http://dx.doi.org/10.5772/55229

\section{Introduction}

Mosquito-borne diseases, including malaria are undergoing a global resurgence [1-7]. The factors responsible for the re-emergence are very complex, and management requires integrated cooperation at many levels, however, a need to better understand the ecology of disease vectors remains critical for any control program to succeed. In the case of malaria, the spatial and temporal changes in anopheline mosquito abundance, quantification of transmission potential of vector populations, characterizations of climatic conditions, and description of distributions of host (human) populations are necessary prerequisites for predicting high-risk malaria areas and implementing an effective disease control program [5, 8]. Tools such as remote sensing and geographic information systems (GIS), which are increasingly being used in studies of disease transmission and vector ecology have greatly enhanced our abilities to analyze landscape level relationships of vectors and diseases. Yet these tools can be successfully used only in combination with a thorough understanding of ecologic and epidemiologic processes of disease transmission.

Among the most important determinants of adult mosquito abundance and distribution is the presence and quality of larval habitats. ${ }^{1}$ An understanding of the dynamics and productivity of larval habitats in the changing environment is required if efforts to model and predict adult abundance and ultimately limit the disease spread are to succeed [8-12]. While biology of adult mosquitoes has been reviewed from multiple perspectives [13-15], there has been no recent comprehensive review of mosquito larval habitats. ${ }^{2}$

1 terms larval habitat, breeding site, breeding habitat have been used interchangeably for descriptions of places where mosquito females oviposit eggs, larvae hatch, grow and pupate [16]. We will be using the term larval habitat throughout the paper.

2Anopheles species included in Sinka's et al [17] list of dominant vector species plus An. vestitipennis have been included in this review. 
A vast amount of literature on malaria vectors is available. More than 60 years ago, Marston Bates wrote in the Introduction to his The Natural History of Mosquitoes: "Mosquitoes in general, and the malaria carriers in particular, have been the subject of a tremendous amount of study, whose results have been reported in the voluminous literature. Much of this literature is an uncritical accumulation of facts that were easy to record, or of facts that were related to some momentarily fashionable subject of study, or of facts that were needed for the attainment of some immediately practical objective. This accumulation awaits to be converted into an orderly and useful structure of knowledge" [18]. It is hard not to feel the same today, with the Web of Science responding with $>600$ references to an inquiry for Anopheles larval habitats. We won't be able to provide "an orderly and useful structure of knowledge" in this short chapter, but we will attempt to cover a few important topics:

-History of description of larval habitats

-Determinants of larval habitats

-Habitat selection

-Landscape context

-Human impact and adjustment to new habitats

-Implications for vector control

-Future priorities

Research and reporting efforts and resulting available information are disproportionately distributed and heavily skewed towards the most important malaria vector, An. gambiae with over 5440 references in the Web of Science, followed by An. stephensi, An. arabiensis and An. funestus with 1557, 744 and 537 references respectively. The majority of remaining species from Sinka's [17] list are referenced < 200 times with the exception of An. albimanus, An. quadrimaculatus, An. darlingi and An. dirus referenced 592, 456, 264 and 255 times, respectively. However, in most cases these species are primary vector species. In considering potential vector replacement following the environmental change (see examples further in the text) it will be important to keep in mind that secondary, little studied and less efficient, vector species might be found replacing primary malaria vector species.

\section{History of description of larval habitats}

Much of what we know about the detailed behavior of individual insect vectors resulted from observations made during the pre-DDT era of the 1920's and 1930's [8, 19], when programs for malaria control through environmental management and regular larvicidal treatment of larval habitats were developed across Europe, Middle East, Asia, and the Americas [20, 21]. Examples of successful treatment schemes [21] show that they were all accomplished based on a good knowledge of larval ecology. The concept that the prevalence of malaria can more effectively be reduced by destroying vector mosquitoes in their adult stage than in their aquatic, larval 
stages became central to antimalarial efforts practiced throughout the world's tropical regions beginning first with pyrethrum and later with DDT spraying. Success of those efforts led startup of the Global Malaria Eradication Strategy, GMES [20, 22]. One of the unfortunate consequences of GMES was a substantial reduction in funding for research related to larval ecology, it was even credited with "exterminating more medical entomologists than mosquitoes" [20]. However, as early as 1983, Service [23] pointed out that "the general disillusionment with chemical control methods has led to the resurrection of biological control from the pre-DDT era" and although funding has not been easy to come by, the 1990's saw an exponential increase in studies on larval ecology and larval habitats. Laird's The Natural History of Laval Mosquito Habitats [24] provided an important source of information.

Although earlier papers are not often cited in the contemporary literature, there are several reasons why older papers are important and should not be ignored:

They provide records of species distributions: The older papers often describing simple surveys or even just few locations where a particular species was found provide historical evidence of species distribution prior to human interference [25, 26]. Example: Positive records of the presence of An. darlingi in southern Belize (then British Honduras) published by Komp [25] and Kumm and Ram [26] and a report of absence of this species 30 years later by Bertram [27], made one of the authors of this chapter (DR) suspects that disappearance of An. darlingi was most probably a response to DDT house-spraying [28]. The species was eventually recorded again from Belize (a consequence of the interruption of DDT-spraying?). The whole story points to the need to continuously study changing roles of malaria vectors in different geographical areas.

They contain important ecological and ecophysiological observations: Already in the 1940's mosquito entomologists realized what many recent papers present as a new discovery, i.e., that human interference can lead to a vector change. As described by Muirhead-Thomson [29] from the coastal zones of Sierra Leone, draining and dyking of mangroves, which used to be very productive habitats for $A n$. melas, and changing land use to rice cultivation, resulted in very productive habitat for An. gambiae and eventual replacement of An. melas by An. gambiae. Goma [30, 31] discarded a long time belief that high incidence of malaria in Uganda is related to the extensive papyrus swamps hypothesizing $[30,31]$ and eventually experimentally proving [32] that interior of a papyrus swamp is unsuitable for anophelines and only the swamps altered by human activities are significant providers of larval habitats. Numerous interesting observations and results of simple experiments on oviposition and larval development as influenced by environmental factors were published [18, 33] and are well summarized in Bates's Natural History of Mosquitoes [34].

There can be a good information on well executed larval control: A series of detailed studies on larval habitats originated from the US Tennessee Valley Authority, TVA (TVA is a federally owned corporation in the US created in 1933 to provide navigation and flood control, electricity generation, fertilizer manufacturing and economic development in the Tennessee Valley, a region strongly affected by the Great Depression; http://www.tva.com/abouttva/history.htm). 
This watershed area of the fifth largest river system in the United States was transformed into a series of reservoirs encompassing more than 11,000 miles of shoreline. Because the impoundment of the river provided enhanced breeding opportunities for An. quadrimaculatus in (then) malaria-endemic region, antimalarial measures were required as integral parts of all TVA projects. The general philosophy was to control mosquito breeding through natural measures and limit larvicidal and other temporary controls to an absolute minimum [35]. Papers by Hinman et al [36], Penfound [37], Hess and Hall [38], Hall [39] focused on the importance of aquatic vegetation in anopheline larval habitats (see section on Vegetation).

\section{Older correlative studies can provide a good starting point for hypotheses testing through} experimental studies: Starting in early 1990's there is a progression of studies that include habitat characteristics and attempts to relate the presence of larvae to these characteristics [17, 40-51]. An important change compared to the majority of older papers was that in these correlative studies, environmental characteristics of both, larvae positive and negative habitats were recorded. As more information became available on the relationships between larval presence and habitat characteristics, attempts to classify anopheline larval habitats appeared. As an example Rejmankova et al. [44] classified larval habitats of An. albimanus on the coastal plain of Chiapas into 16 habitat-types based on the dominant aquatic vegetation. The goal was a hierarchical system of habitat classification that could be universally used for larval habitat description in the study area and it became a basis for many future studies on larval ecology by the Tapachula-based Center for Malaria Studies [52-54]. The analytical methods and hierarchical system described in Rejmankova et al [44] article are applicable to a wide range of studies on phytoecological relationships of vectors to aquatic habitats.

The need for regional classification of larval habitats into higher units became more urgent with the increasing use of remote sensing technology in malaria vector studies [55-57]. The step-wise approach (paradigm) advocated by Roberts and Rodriguez [58] became widely applied [59, 60]. These steps included the following: 1) developing an understanding of vector ecology and defining the environmental determinants for its presence and abundance (this step is based on field studies); 2) constructing a database that characterizes the landscape elements associated with the important aspects of vector biology and human habitation (RS and GIS are suitable tools for this step); and 3) formulating and verifying predictions of vector abundance.

Recently, studies describing larval habitats of anophelines were included in the global database on 41 dominant vector species, DVS, of human malaria. The contemporary distribution of each of the DVS, alongside a comprehensive description of the ecology and behavior of each species, has been published in a series of papers by Sinka and coauthors [17, 61-63]. The authors stated that simple, universal species-specific statements regarding the biology of these vectors are nearly impossible due to the behavioral plasticity of most species, in some cases sympatric distributions of sibling species, changing taxonomic categorization and the influence of environmental disturbance, all contributing to a high level of complexity. 
While the descriptive and correlative studies of larval habitats have mushroomed in the 1990's and 2000's, good experimental studies explaining the hypothetical relationships between larvae and the habitat characteristics are still relatively lacking. They are increasingly called for [11, 22], e.g., by proposing development and application of enclosed, pathogen-free, semifield mesocosms in which vector populations can be experimentally manipulated. There are a few exceptions such as Goma's [31] study from the papyrus swamps in Uganda. Based on his observations on the absence of An. gambiae larvae from the swamp interior, Goma hypothesized that the larvae are not found there because the conditions are unfavorable for their development. He conducted a series of experiments in which known amounts of larvae of different instars were placed in floating cages in different locations throughout a swamp and confirmed that larvae in the swamp interior suffered significantly higher mortality and those surviving took longer to develop into adults than larvae in cages placed at the swamp periphery. The high mortality has been later explained as a result of inhibition of larval breathing due to the surface layer of oil produced by papyrus [64]. For other examples of hypotheses driven experimental studies see, e.g., [10, 65-76] and other examples provided in further text.

\subsection{Dichotomy between medical entomologists and ecologists in larval studies}

There has been quite a deep divide between medical entomologists and ecologist in their approach to studying mosquito larval habitats [22,77]. Medical entomologists generally study larval habitats with the focus on design of efficient control interventions and often don't realize that it is the ecological approach to studying larval habitats in the context of other ecosystem components that can eventually lead to a thorough understanding of the larvae - habitat relationships. A relatively small number of researchers realize that filling the gap between ecologically based and epidemiologically based information is a necessity [77]. As Chase and Knight [78] put it: because larval mosquitoes are components of a much larger metacommunity of interacting species, the interplay between biotic interactions (competitors and predators) and abiotic constraints (temperature, habitat drying) is essential for understanding the controls on mosquito abundance. By placing mosquitoes into a broader community context, a much better predictive framework can be developed for understanding and predicting year-to-year variation in mosquito abundances $[79,80]$. Ecology should-like other basic disciplines such as molecular biology and bioinformatics-be considered an enabling science essential for defining the target product profiles of completely new control technologies and delivery systems [22].

\section{Environmental determinants of larval habitats}

Larval habitats or breeding sites - places where eggs are laid, larvae hatch, change instars, pupate, and adults emerge - are primary drivers of adult distribution, abundance and fitness $[5,9,10,81]$. They are always composed of water bodies, natural or man-made, permanent or 
temporary, large or small, freshwater or saline. The mosquito reproduction is successful only if larval habitats remain stable for a duration equivalent to the development of immature stages [82]. The great diversity of habitats, often combined with inaccessibility, makes studies of the ecology of larval anopheline mosquitoes methodologically quite difficult [9].

Larval densities are controlled by interactions between abiotic (hydrology, temperature, light/ shade, $\mathrm{pH}$, salinity, nutrient availability) and biotic (predation, competition) factors [78, 83-85]. For comprehensive analyses of patterns in the productivity of larval habitats the studies should incorporate a landscape context, because presence and abundance of mosquito larvae in aquatic habitats and consequently the number of adults capable of malaria transmission are regulated by a variety of ecosystem processes operating and interacting at several organizational levels and spatial/temporal scales [86]. The conceptual scheme in Figure 1 summarizes the main factors and processes important for good understanding of interactions between larvae and their habitat characteristics in the larger ecosystem context. Humans can affect habitat availability and quality through ecosystem and landscape changes such deforestation/ reforestation, desertification, irrigation and other hydrological changes, and agricultural practices (see further). In the following text we will focus on the main determinants of larval development.

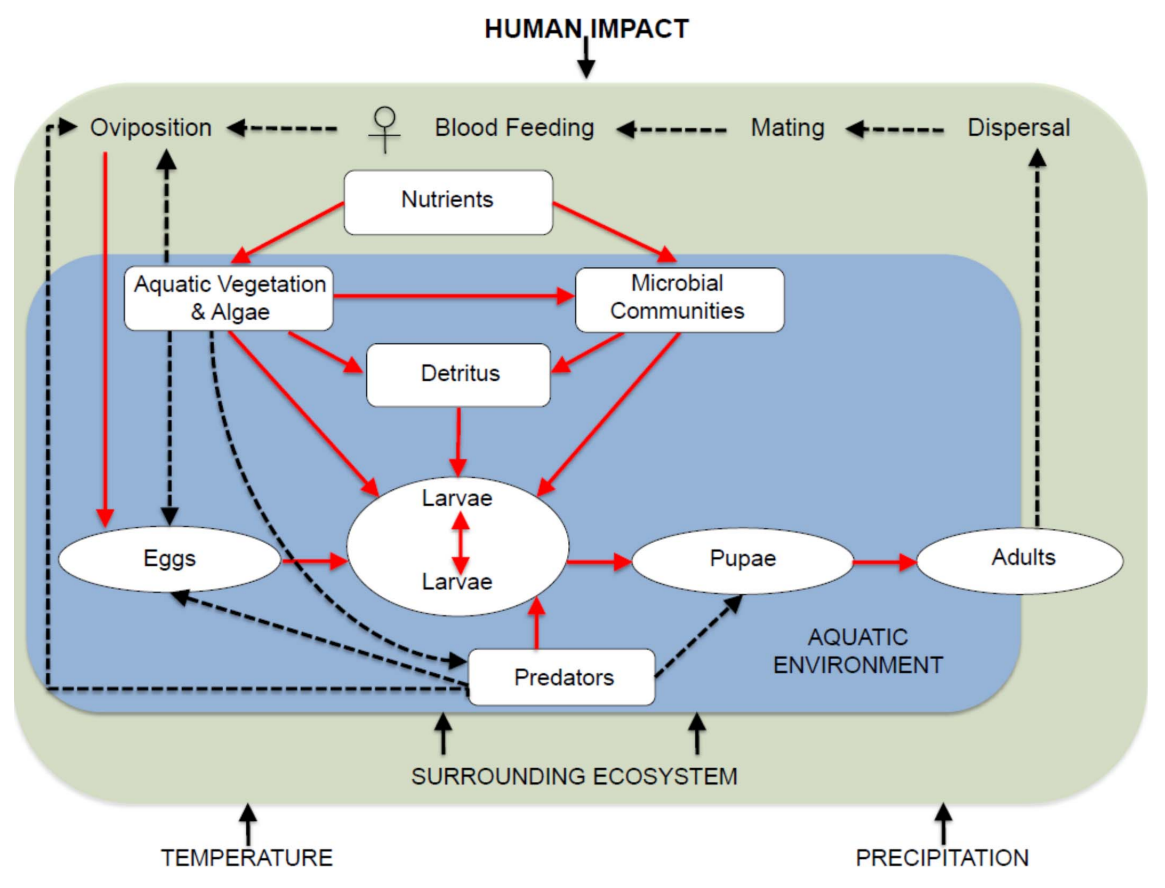

Figure 1. Relationships between larval development and environmental factors on both habitat and ecosystem level. The relationships reviewed in the chapter are indicated in red. 


\subsection{Temperature}

Temperature affects all the important processes such as the rate of larval development and survivorship, pupation rates, larval-to-adult survivorship and larval-to adult development time [81, 87-89]. Water temperature is influenced by various parameters, such as local climate, water depth and movement, habitat size and geometry, land cover type or canopy overgrowth, presence of vegetation and/or algae, soil properties and turbidity [81]. Despite its importance, there are not many detailed outdoor studies on the temperature of larval habitats and the available data are hard to compare due to different methods of temperature measurement (air temperature vs. water temperature; data loggers vs. hand-held thermometers). Available data on An. gambiae point to a consensus that one of the main reasons for higher productivity of An. gambiae and An. funestus in habitats associated with agricultural crops or swamp margins is higher temperature as compared to shaded dense papyrus swamps [72,90,91]. Additional proof comes from Wamae et al [88] who compared An. gambiae densities in shaded (by napier grass, Pennisetum purpureum) and unshaded water channels in reclaimed sites in Western Kenya highlands. In these studies, the shading reduced anopheline larvae by $>75 \%$, apparently due to $\sim 3$ degrees $C$ reduced water temperature. High water temperature pools (30-33 degrees C) were reported as the most productive habitats for An. gambiae in Gambia [92]. In South America, Marten et al [93] found the majority of An. albimanus larvae on the coastal plain of Colombia associated with sun-exposed sites with a mid-day temperature range of $27.5-30.0^{\circ}$ C. Pinault and Hunter [94] report minimum water temperatures that might limit the upper altitudinal distribution of An. albimanus $\left(18.7^{\circ} \mathrm{C}\right.$ ) and An. pseudopunctipennis (16.0 $\left.{ }^{\circ} \mathrm{C}\right)$. Larvae are not generally able to survive temperatures over 40 degrees $C$ as documented by MuirheadThomson [29] for An. minimus, (but see An. bwambae in hot springs, [95]). Recent detailed study on the longevity and mortality of An. gambiae under a wide range of temperatures [87] concluded that under extremely cold $\left(10-12^{\circ} \mathrm{C}\right)$ or hot $\left(38-40^{\circ} \mathrm{C}\right)$ temperatures all larvae died within a few days. While the low temperature range is rarely experienced in larval habitats of An. gambiae, the higher temperatures are frequently encountered in most tropical regions. In nature, however, such high temperatures occur for no more than a few hours and larvae may survive these short periods.

Paaijmans et al $[81,96]$ stressed the importance of temperature fluctuations for larval development. The authors provided a conceptual model of radiation and energy fluxes at the airwater and soil-water interfaces of small, shallow and clear water pools and did filed measurements comparing smaller and larger water bodies [81]. In general, the small-sized water pool reacted more dynamically to suddenly changing meteorological variables and experienced larger fluctuations. Several important conclusions follow from these experiments: The top layer (upper $2 \mathrm{~mm}$ ) of each water pool differed in temperature from the layers underneath, which has important consequences for larval dynamics as anopheline larvae generally live horizontally near the air-water interface of aquatic habitats [66]. There can be large differences (> 10 degrees C) between air and water temperature. Larger pools had larger buffering capacity. Mosquito immatures can be exposed to a wide temperature range under natural conditions and they are apparently evolutionarily adapted to their direct environment. The observed differences between air and water temperature have important consequences and 
should be carefully employed for ecological models that use the air temperature as an input parameter for larval development.

\subsection{Light}

There are species occurring mostly in sun-exposed environments such as An. gambiae s.s., $A n$. albimanus, An. pseudopunctipennis, members of the An. sundaicus complex, An. sinensis, An. aconitus etc., while others seem to prefer shaded water bodies (An. funestus, An. vestitipennis). The question of whether sun or shade has a direct effect on the development of larvae or impacts them indirectly through the effect of temperature on food source development has not been answered, although some laboratory experiments seem to show that light is not an important direct factor [83, 97]. It is possible that in some instances, larvae are positively correlated with shaded environment only because shade of trees reduces drying speed of the pools [98]. Little is known about the effects of darkness on larval development in Anopheles species. It has been shown, however, that light deprivation causes a significant reduction in the development of adult An. stephensi when larvae were bred in the absence of light [33]. In the dark treatment group, only about $60 \%$ of pupae transformed into adults.

\subsection{Salinity}

There are large differences in the tolerance of anopheline larvae to water salinity. While the majority of anopheline larvae are found in fresh waters, there are several species that show high salinity tolerance and are associated with coastal malaria transmission. Anopheles melas and An. merus within the An. gambiae complex are examples from Africa [61]. Anopheles farauti s.s. and An. irenicus (formerly designated An. farauti No. 7) in the Farauti Complex are reported to be salinity-tolerant in Australasia [63, 99]. Malaria vectors of the An. sundaicus complex in Southeast Asia are well known brackish water breeders [100, 101]. On the American continent an example of salt tolerant species is An. aquasalis [48, 102].

A major challenge faced by all mosquito larvae is the tendency for larval habitats to fluctuate widely in salinity due to changes in rainfall and evaporation [13]. Organisms living in brackish and saline environments have evolved various mechanisms of coping with increased salinity, and in order to survive in these conditions, they have to be able to regulate their osmotic potential. Larvae of salinity tolerant mosquito possess cuticles that are less permeable to water than freshwater forms, and their pupae have thickened and sclerotized cuticles that are impermeable to water and ions. Larval survival depends upon the ability to regulate hemolymph osmolarity by absorbing and excreting ions [103]. Osmoregulatory mechanisms vary among various mosquito genera, for example An. albimanus larvae osmoregulate through rectal ion excretion and the larvae undergo a dramatic shift in rectal $\mathrm{Na}+/ \mathrm{K}+-\mathrm{ATPase}$ (an enzyme important for ion regulation) localization when reared in freshwater vs. saline water [103].

Saltwater tolerance is a trait that involves ionic regulation at the aquatic larval stage, and it appears to have been a factor in the adaptive radiation of the A. gambiae complex into diverse larval habitats. A mechanistic understanding of the physiology and genetics of ion regulation 
is important because it can open up new classes of larvicide [104]. Additionally, increasing amounts of saltwater pools and puddles associated with natural disasters (tsunami), land subsidence, or sea level rise would facilitate increased breeding of brackish water malaria vectors (e.g., An. sundaicus) and may increase the risk of malaria outbreaks $[105,106]$.

\subsection{Hydrology and geomorphology}

Hydrology of a region, i.e., distribution and seasonal dynamics of lotic and lentic water bodies is determined by the geomorphology and precipitation patterns [107, 108]. Water quality in these different water bodies is influenced by rock and soil chemistry, vegetation of the surrounding landscape, and human activities. Both hydrology and water chemistry determine the type of aquatic vegetation present in lakes, pools, and streams [42]. Geomorphological parameters such as elevation, slope, aspect, and ruggedness play an important role in malaria transmission as exemplified, e.g., by Atieli [108] who found broad flat-bottomed valleys in Kenya Highlands to have a significantly higher number of Anopheles larvae/dip in their habitats than the narrow valleys. Heavy rains in the tropics can be detrimental to larval survival. In particular, rainstorms are known to flush mosquito larvae from their breeding sites [109, 110] - but see Manguin et al. [47] who reported survival of $3^{\text {rd }}$ and $4^{\text {th }}$ instar larvae in clumps of detritus that was stranded in trees and shrubs in the wake of the flood.

\subsection{Vegetation}

Many shallow water bodies are dominated by aquatic plants - both microphytes (algae and cyanobacteria) and macrophytes.

Aquatic macrophytes, often also called hydrophytes, are key components of aquatic and wetland ecosystems. As primary producers, they are at the base of herbivorous and detritivorous food chains, providing food to invertebrates, fish and birds, and organic carbon for bacteria. Their stems, roots and leaves serve as a substrate for periphyton, and a shelter for numerous invertebrates and different stages of fish, amphibians and reptiles [66, 111]. Biogeochemical processes in the water column and sediments are to a large extent influenced by the presence/absence and type of macrophyte, and macrophytes can also have a profound impact on water movement and sediment dynamics in water bodies [112].

Phytoecological relationships of many species are strong enough to indicate presence or absence of mosquitoes according to presence or absence of associated plants [44]. The effect of aquatic plants on mosquito oviposition and larval survival and development, particularly among the anophelines, has been recognized since the early 1930's [38, 39, 66, 113-115]. Many aquatic plants provide food and protection for mosquito larvae and create favorable conditions for oviposition. Of special importance is the interface of air-plant-water, which has been termed the intersection line [38]. The intersection line is important to anopheline larvae because it is where the larvae find food and shelter and adults find the water surface broken up into numerous quiet cells favorable for ovipositing [19, 66]. A number of studies have documented a positive correlation between larval density and amount of plant cover or intersection line, e.g., [38, 115-118]. Plants provide favorable conditions for anopheline production if they 
continuously intersect the water surface during the mosquito breeding season. Collins and Resh [118] present a table showing the evaluation of common wetland plants for habitat suitability including the intersection line value.

Aquatic macrophytes are extremely diverse taxonomically, morphologically and functionally. Thus it is not surprising that different groups of macrophytes provide suitable habitats for different mosquito species (Figure 2). Of the four major macrophyte categories, i.e., freely floating, emergent, submerged, and floating-leaved [112], emergents generally provide the largest number of intersection lines. The positive benefits associated with aquatic macrophyte cover, and dense patches of emergent plants in particular, should result in a strong selective advantage (i.e., increased fitness) to individuals that choose high density macrophyte patches as habitat [66]. Selective pressure for such habitat preferences should operate on both larval and adult stages of Anopheles and the strong preferences of larvae and ovipositing adults for higher density patches of Myriophyllum were indeed observed by Orr and Resh [66].

While the majority of anopheline species are rather generalists and not very selective for a particular type of vegetation, there are others with tighter phytoecological associations. Anopheles gambiae is an example of a generalist whose larval habitats are shallow temporary water bodies with algae or short grasses but also devoid of any vegetation [61], see Figure $2 \mathrm{H}$ and papers of Mutuku et al. [119] and Ndenga et al. [89] for illustrations. Among examples of an extremely close association are the larval habitats of An. pseudopunctipennis, which are typically sun-exposed streams with abundant filamentous algae [42, 94, 120-124], see Figure 2E. The selection of filamentous algae by An. pseudopunctipennis has been confirmed by oviposition experiments [125, 126]. Similarly, the presence and abundance of An.farauti larvae was positively associated with filamentous algae in Solomon Islands [99]. Another species whose habitat can be clearly defined by vegetation presence is An. vestitipennis. Numerous reports confirm its association with tall dense macrophytes and/or flooded swamp forest [127-130] see Figure 2A. It is perhaps the preference of An. vestitipennis for a shaded environment generally that results in it being associated with these two types of habitats [129]. Preferred habitats for An. darlingi are patches of detritus often accumulated behind a fallen stump, or vegetation at the shady edges in slowly running streams and rivers $[26,42,47,73$, 82] see Figure 2F. Barros et al [82] call these habitats "microdams" and they found the presence of microdams to be the most important parameter determining spatial distribution of $A n$. darlingi larvae in northern Brazilian Amazon. Achee et al [73] experimentally evaluated the importance of floating detritus patches and overhanging bamboo for An. darlingi habitat selection using floating screened enclosures placed in a river at a location with documented presence of both larval and adult An. darlingi populations. The detritus treatment had a significantly higher average count of $A n$. darlingi larvae documenting that females preferentially oviposited in this habitat.

Even with these tight associations, there are often exceptions, e.g., An.pseudopunctipennis found in tall dense macrophytes (Schoenoplectus californicus) in the coastal zones of Peru (DR, ER unpublished data), or even without vegetation [124], but these snapshot observations on larval presence don't really provide information about survival and adult fitness. 


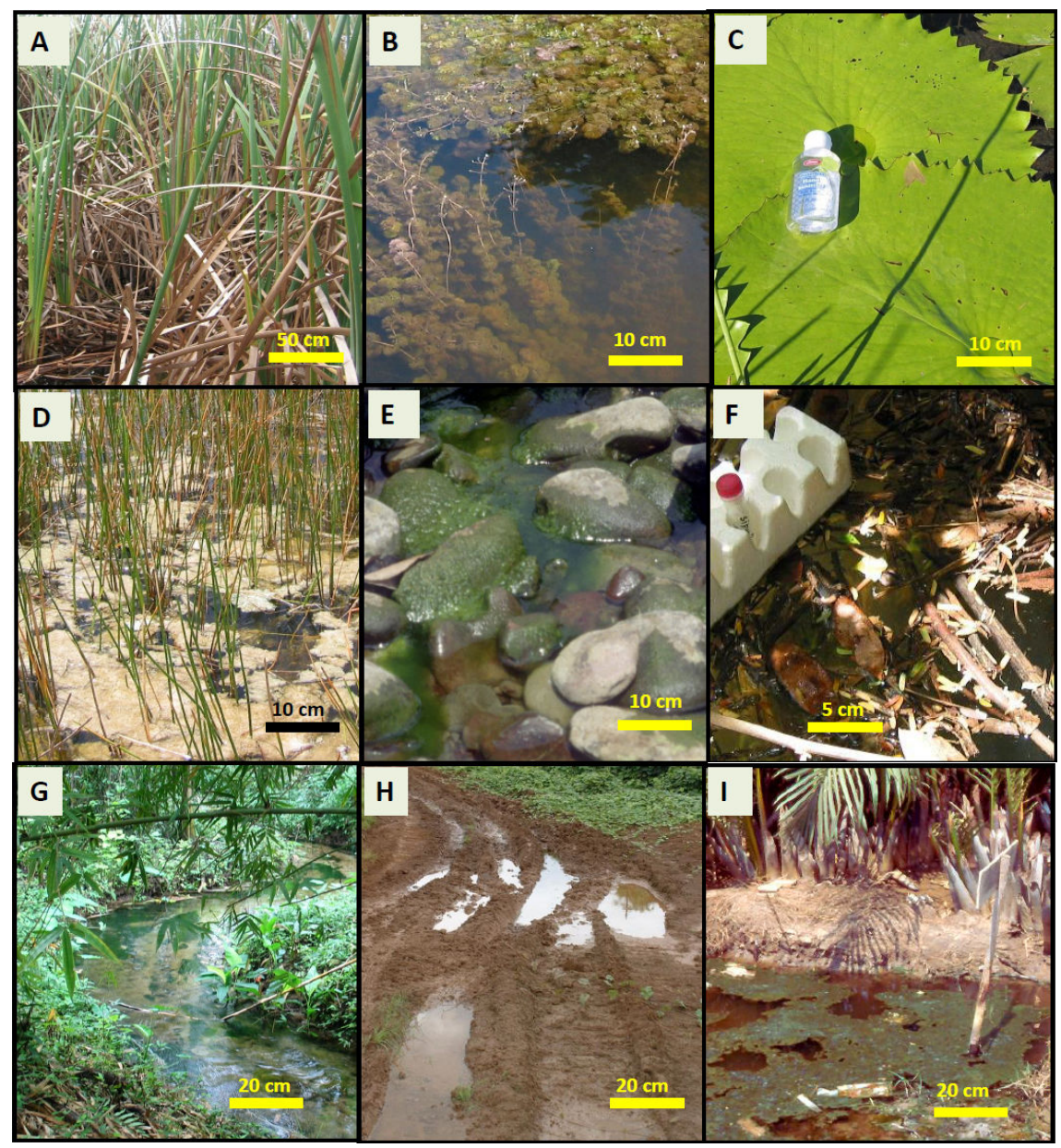

Figure 2. Examples of various larval habitat types as defined by vegetation. A: Freshwater marsh with tall dense macrophyte, Typha domingensis, a typical habitat for Anopheles vestitipennis; B: River edge vegetation dominated by a dense submersed macrophyte Cabomba aquatica, a potential habitat of An. darlingi; C: Marsh dominated by floatingleaved macrophyte, Nymphaea ampla, an example of an environment where larvae are typically not found; D: Marsh with sparse emergent macrophyte, Eleocharis cellulosa, interspersed with floating mats of cyanobacteria, a typical habitat of An. albimanus; E: A stream with filamentous green algae, a typical habitat for An. pseudopunctipennis; F: Detritus in a protected riverine environment, a typical habitat of An. darlingi.G: Small, partially shaded stream with vegetated margins, a tyical habitat for An. minimus; H: An. gambiae habitat from Equatorial Guinea (Malabo region); I: Stagnant pool of water with floating mats of algae, a habitat of An. epiroticus (Sundaicus complex) from southern Vietnam. Note the different scale bars.(Photo G \& I courtesy of Sylvie Manguin; photo H courtesy of Pierre Carnevale).

\subsection{Rice fields}

Considering the large extent of rice fields in the areas with endemic malaria, they deserve their own subchapter. The changing crop practices, such as the shift to irrigated wetland rice affect 
Anopheles vector populations, increasing the extent of larval habitats and transmission of malaria [131]. Irrigated rice cultivation extends the time in which vectors breed and in countries with two crops of rice per year, anopheline breeding and biting rates extend well beyond their usual seasons [131, 132].

The aquatic community in rice fields is a dynamic system related closely to rice plant growth, rice cultivation practices, and seasonal climatic changes [133-135]. Each mosquito species often has a preference for a particular phase in rice field development, which may result in an orderly succession of species as the rice plants develop and mature [136]. The pioneer colonizers are typically sun-preferring species, such as An. gambiae (Africa) An. albimanus (Central America), and An. fluviatilis and An. culicifacies (Oriental region); but when the rice grows taller it shades the water and shade-preferring species, such as An. funestus (Africa), An. umbrosus (India), An. hyrcanus group (Asia), An. leucosphyrus complex (Malaysia), An. freeborni (North America), An. punctimacula (South America) usually become more abundant [131, 136]. The abundance of aquatic macroinvertebrates, including predators, also changes during the growth of a single rice crop [76, 135, 137]. Compared to Asia and Africa there is less documentation of linkages between rice cultivation and disease in Latin America, although in parts of Mexico and Venezuela rice appears to be associated with seasonal increases in malaria incidence [138].

\subsection{Food sources}

Aquatic plants (both micro- and macrophytes) provide protection from predators and, together with trees and shrubs, contribute detritus that supports the bacterial community, which, in turn, serves as food for larvae [139]. An understanding of the spatial and temporal distribution of the dietary resources available to larval mosquitoes in their natural habitats could clarify the relationships among food availability, vector competence, and mosquito fitness $[19,140,141]$. Yet, the quantity and quality of food sources available to larvae is often ignored in the study of larval growth and development [9]. Natural food assemblages of larval mosquitoes are extremely diverse biochemically [142]. Generally, bacteria have been considered the most important of the microorganisms that comprise the food of mosquito larvae [19, 24], and mosquito growth can occur on cultures of bacteria alone [19]. In the water column of aquatic ecosystems, bacteria are the major decomposers of organic matter and the presence of particulate heterotrophic bacterial biomass represents an important link between detritus, dissolved organic matter, and higher trophic levels [143]. This bacterial production is controlled by or directly related to the supply of decomposable organic material. Thus, larval habitats with ample supplies of autochthonous and/or allochthonous detritus are capable of providing sufficient supplies of larval food resources. Experiments with diets also demonstrated that mosquito larvae can develop solely by drinking dissolved nutrients [19]. Larval food sources are not distributed homogeneously throughout the water column. The surface microlayer contains relatively high amounts of nutrients, organic material both particulate and dissolved, and various microorganisms as compared to subsurface water [144]. Anopheline larvae are well suited to utilize food sources from the enriched surface layer as they typically feed at the surface of the water where they engage in interfacial feeding behavior [13, 144]. 
Microalgae and/or small cyanobacteria can also serve as an important food source [19, 53, 93, 145]. Gimnig's et al [10] study demonstrated that larval grazing reduced algal abundances and biomass by an order of magnitude, and changed microeukaryote community structure. Changes in this algal food resource due to larval consumption almost certainly led to the observed density-dependent responses in larval development. Kaufman et al [145] conducted experiments to investigate the importance of algal food resources for larval growth and adult emergence of An. gambiae in simulated larval habitats in Kenya. Their results confirmed the importance of algal biomass in the surface microlayers of larval habitats to larval development and production of An. gambiae adults. They also showed that soil quality in these ephemeral larval habitats is important as the growth of algae depends on nutrient availability, particularly phosphorus (P). Thus soils releasing more P after flooding would support more algae that can feed more larvae.

While some microalgae are an important food source, other algae can be harmful to anopheline larvae. Marten's [146] review concludes that many species of green algae in the order Chlorococcales are resistant to digestion by mosquito larvae. Larvae are unable to complete their development if indigestible algae are numerous enough in the aquatic habitat to prevent the larvae ingesting enough other food to satisfy their nutritional needs. In addition, cyanobacteria (blue-green algae) can potentially kill larvae by toxins they produce [53].

\subsection{Essential fatty acids}

Lipids are an important food component for mosquito larvae because they provide a concentrated form of energy storage and a source of essential biochemical nutrients. Fatty acid (FA) constituents of lipids are present in a great structural variety, and are increasingly being used as chemical markers of biogeochemical processes and trophic relationships [147]. While the saturated palmitic acid (16:0) is often one of the most abundant fatty acids in lipid extracts, the interest of nutritional studies has concentrated on polyunsaturated fatty acids (PUFA) with two or more double bonds [148]. Some of these PUFAs are essential to the normal function of cells and they or their corresponding precursors have to be obtained in animal diets. In most animals, the 18-carbon chain, 18C, PUFAs can be converted to the longer-chain essential PUFAs, specifically arachidonic acid, ARA, eicosapentaenoic acid, EPA, and docosahexaenoic acid, DHA. Mosquitoes seem to be an exception because their dietary FA requirements cannot be satisfied by the C-18 PUFAs [149, 150]. They require some 20 - and 22-C polyunsaturated fatty acids, EPA, ARA and DHA and without an adequate supply of these PUFAs they are not able to fly $[149,150]$. Adult females may get these from a blood meal [151] but these PUFAs are believed essential in thelarvalstage for flightmuscledevelopment. Theunderstanding of the spatial and temporal distribution of dietary resources available to mosquito larvae is needed in order to clarify the relationship among food availability, vector competence, and mosquito fitness. Not only does the nutrient availability within the habitat have to meet a minimum dietary requirement for proper larval development, but the food consumed in the larval stage is critical for a number of physiological processes that impact adult performance [152].

Kominkova et al. [153], in order to reveal the importance of feeding habitats for the nutrition of anophelinelarvae, analyzed theFA composition of larvaeof threemalaria transmitting mosquito 
species An. albimanus, An. vestitipennis and An. darlingi and their corresponding habitats. They found that habitats were generally low in essential PUFAs and there were no significant differences among the FA composition of habitat samples. However, there were significant differences in FA composition of larvae. Anopheles darlingi contained significantly higher amounts of FA, specifically the linoleic acid. Large differences in PUFA content were found between field collected and laboratory-reared An. vestitipennis larvae, however, there were no differences in the total dry weight of the $4^{\text {th }}$ stage larvae between the wild vs. laboratory-reared populations. Total FA in both larvae and samples of habitats of An. albimanus and An. darlingi were positively correlated with the concentration of particulate organic carbon and nitrogen (POC, PON) in their respective habitats, but no such correlation was found for An. vestitipennis. This study revealed that PUFA are a good indicator of nutritional quality although factors controlling the success of anopheline developmentinlarval habitats arelikely tobemorecomplex and include, among others, the presence of predators, pathogens and toxins.

\subsection{Species interactions (predation and competition)}

Understanding species interactions such as competition and predation, across environmental gradients provides insight into how assemblages of mosquitoes are structured. This information is then critical for proper application of biological control [154]. The topic of competition and predation is a good example of the dichotomy in the approach to studying larval stages of mosquitoes. Many papers focus on use of predators for larval control [155-157]. There is a lack of studies focusing on larval competition and predation in the ecological context such as habitat size and temporal stability. But it is what influences the prevalence, pattern, and effects of species interactions across freshwater communities [158-160]. Spatial variation in biotic interactions can explain spatial variation in larval mosquito densities and ultimately the abundance of adult mosquitoes [78, 158]. Studies on predators of mosquito larvae go way back into history. Hinman [161] in his summary of predators on mosquito larvae lists over 100 references. Competition on the other hand is less studied even though interspecific competition for limited resources can be quite important and has been shown to have large effects on mosquito larvae. Mosquitoes compete with tadpoles [162, 163], other species of mosquitoes [164] and cladocerans [165].

Relative impacts of competition and predation change across a gradient of habitat size and permanence [159]. Bodies of water that may serve as larval habitats form a gradient from small and highly ephemeral to large and permanent. At the small, ephemeral end of this gradient, large long-lived predatory organisms (namely fish) are often absent, and aquatic organisms need to develop quickly. These conditions favor rapid growth and development, active foraging, movement, and competitive ability. As water bodies become larger and temporally more stable they can support more diverse community of larger, longer-lived predators. This increase of diversity, number, and voracity of predators favors refuge use, inconspicuousness, predator deterrence, and slow growth and development [159]. Organization of mosquito communities can be viewed in the same way. Interspecific competition among mosquitoes can be more important as a determinant of community structure in small ephemeral habitats, whereas predation can be more important in large permanent habitats [159]. Limited evidence 
suggests interspecific competition and cannibalism among mosquitoes is common in small pools [70], but comprehensive review of the ecology of competitive interactions of mosquitoes is lacking.

Natural predators of mosquito larvae are quite diverse and include the tadpole stages of amphibians [166], planktivorous fishes [165] and aquatic insects (Coleoptera, adult Heteroptera and larval Odonata). There is a range of papers reviewing predators on mosquito larvae and their potential use in biological control. Kumar and Hwang [167] provided an excellent review of larvicidal efficiency of amphibian tadpoles, larvivorous fish, cyclopoid copepods and aquatic insects. Mogi [168] reviewed insects and invertebrate predation on different life stages of mosquito. Quiroz-Martinez and Rodriguez-Castro [169] summarized the information on arthropods (insects, mites and spiders) that prey on mosquito larvae and discussed the potential of these predators in mosquitoes' biological control programs. Shaalan and Canyon's [156] review covered the predation of different insect species on mosquito larvae, predator prey-habitat relationships, co-habitation developmental issues, survival and abundance, oviposition avoidance, predatorial capacity and integrated vector control. Rozendaal [170] and Chandra et al [171] reviewed information on different larvivorous fish species and the present status of their use in mosquito control.

Despite thorough reviews and much information on different types of predators, there is a paucity of well-designed experimental studies verifying the long term effect of predators on mosquito populations. Although predation has been suggested as one of the important regulation mechanisms for malaria vectors in long lasting aquatic habitats, the predatory efficiency of potential predators is largely unknown [22, 157]. Research on predation of mosquito larvae has relied partly on the identification of larvae in the predators' gut serological methods $[172,173]$, partly on correlative field observations evaluating the abundance of larvae and predators in the habitats $[52,174]$, and partly on laboratory feeding studies [157]. However, many predators that have been shown to be highly successful in eliminating target prey in the laboratory do not show a similar response in their natural habitats [75, 155]. The most basic question is whether predators have an important impact on mosquito populations in the field in the presence of alternative prey. Collins and Resh [118] listed the ecological factors affecting predation that should be considered when designing predation experiments: 1) dietary preference for mosquitoes, 2) abundance of alternative pray; 3) degree of congruity between habitats of the predator and target mosquito; 4) density of predators within habitat; 5) density of mosquito population; 6) quality of habitat as a refuge from predator. Among examples of well-designed experimental studies on multiple predator impacts we can cite Kumar et al [155] who compared the control potential of three larvivorous predators commonly co-occurring in the wetlands of tropical and subtropical regions, the mosquito fish Gambusia affinis, the cyclopoid copepod Mesocyclops aspericornis, and naiads of the dragonfly Zyxomma petiolatum, against the larvae of An. stephensi in the presence of alternative cladoceran prey. The presence of the alternative prey significantly reduced larval consumption by all three predators. Kumar et al [155] also discuss the issues related to using non-native mosquito fish considering its potential negative impacts on native assemblages and its lower selectivity for mosquito larvae. 
Mosquito control using fish has focused on a limited number of species, primarily Gambusia affinis and Poecilia reticulata that have traditionally been used for controlling mosquito larvae $[175,176]$. One of the most important concerns when introducing exotic fish for mosquito control is their impact on native species [177] and thus information on the predation role of native species is desirable. Louca et al [175] evaluated the role of larval predation by native fishes in Gambia River and they pointed out that the major impact on larvae was actually exerted by a detritivorous Tilapia, which is a prevailing species in the system that feeds on larvae only opportunistically in small aquatic habitats.

Blaustein [134] documented an unefficient control of anopheline larvae in the rice fields in California. He pointed out that contrary to what a good system should be composed of, i.e., a relatively permanent habitat, a specialist control agent and a relatively abundant pest species, the fish-mosquito-rice field system does not have any of these attributes. In addition, mosquito fish may have indirect positive effects on mosquito abundance; they also feed on invertebrates which are either natural predators (see [178]) or potential competitors of mosquito immatures [165]. Thus, this strategy attempts to control a relatively rare prey species with a generalist predator. The underlying mechanisms of predator-prey relationships need to be more clearly defined in order to use this biological control agent more effectively. There is a general need for field experiments on competition, predation, and mutualism, and on their context dependence across species and habitats [159].

Predation at larval stages can have important evolutionary consequences for mosquitoes [179]. For example, the predation of aquatic immature stages has been identified as a major evolutionary force driving habitat segregation and niche partitioning in the malaria mosquito An. gambiae in humid savannahs of West Africa $[160,180]$. These studies explored behavioral responses to the presence of a predator in wild populations of the M and Smolecular forms that typically breed in permanent (e.g., rice field paddies) and temporary (e.g., road ruts) water collections. The experiments showed that the $\mathrm{M}$ and $\mathrm{S}$ forms modify their behavior in the presence of a natural predator by becoming less active and positioning themselves at the wall of the container. These behavioral modifications suggest that mosquitoes are able to detect a predator's presence, through as yet unknown mechanisms which deserve further investigation.

\section{Habitat selection}

Habitat selection, defined as a process in which individuals preferentially choose and occupy a nonrandom set of available habitats, is of major importance for interpretation of spatial and temporal distributions of populations [139, 181]. The choice for suitable places for female mosquitoes to lay eggs is a key-factor for the survival of immature stages (eggs and larvae). Oviposition site selection has been recognized as critical both for the survival and population dynamics of mosquitoes. It is influenced by several environmental factors [182], including the salinity and turbidity of the water, the size and degree of permanence of the water body, the amount of sunlight, the presence of emergent/floating vegetation and shade, presence of predators, and distance to human habitation $[8,66]$. In general, larvae of anopheline mosquitoes prefer clean rather than polluted water $[8,183]$, although in urban areas in parts of Africa An. gambiae appears to be adapting to new habitats such as rubbish-filled pools, sometimes 
containing sewage $[182,184]$. Larvae of several Asian species (An. dirus, An. punctulatus, An. subpictus) have been reported from muddy and/or polluted waters [63].

In choosing sites for oviposition, females have to consider multiple-and possibly conflicting -factors to arrive at a site selection strategy that will optimize their reproductive success [185]. As many other oviparous species, mosquitoes also avoid oviposition in habitats with high risk of predation to their larvae [154, 186]. Females perceive these different characteristics of their habitats through a set of various cues both positive and negative. Among positive cues, volatile substances released from larval habitats have been implicated as potential olfactory cues mediating oviposition [54,126, 139]. Experimental verification of dose response confirmed that low concentrations of volatile materials extracted from species-specific larval habitat materials increased oviposition, while there was a shift to reduced oviposition at high volatile concentrations. Rejmankova et al [139] also confirmed through reciprocal treatment tests that volatile effect was strongly habitat/species-specific.

Different mosquito species may rely on distinct chemical cues to avoid predators [187]. Mosquitoes that can detect aquatic predators often do so by sensing predator-released kairomones [187], see also review in Vonesh and Blaustein [188]. This was confirmed by preferential oviposition of An. gambiae in containers with clean water rather than water conditioned with predators (backswimmers, Notonecta sp. and tadpoles, Xenopus sp.) [72]. The experiment with Notonecta was later successfully repeated on other strains of An. gambiae by Warburg et al [187].

After oviposition, the main factors determining larval survival are food availability and refuge from predators. Orr and Resh [66] documented microhabitat selection by larvae of An. freeborni. They found that larval distribution throughout the habitat (an emergent macrophyte, Myriophyllum aquaticum) was not random, but that the larvae tended to congregate in denser patches of macrophytes. Observational data confirmed an active mechanism of selection, i.e., larvae actively choose patches with higher plant densities.

Larval habitats of the main malaria vectors in Belize are associated with three distinctly different aquatic environments: marshes with sparse macrophytes and cyanobacterial mats (An. albimanus), tall dense macrophyte marshes (An. vestitipennis), and floating detritus assemblages within freshwater rivers (An. darlingi). To assess species specific habitat suitability, we conducted mosquito transplant experiments [74]. First instar larvae of An. albimanus, An. vestitipenis and An. darlingi were placed in floating containers in the respective habitats of each species. Response of mosquito species to environmental conditions of its own and transplanted habitats clearly showed that each species was performing best in its own habitat. Survivorship of An. vestitipenis and An. darlingi in the An. albimanus habitat was extremely low or none.

\section{Landscape context, remote sensing, GIS}

Larval habitats are not located in a vacuum, they are an integral part of a broader landscape and their environmental requirements should be studied in this context. The landscape level 
approach gained momentum when technologies such as remote sensing (RS) and GIS became widely used in 1990's [55, 57, 59, 60, 189-191] and it has continued improving with the progress in RS technology (see review in Machault and coauthors [192, 193]. Direct measurements of the Earth's hydrological and biophysical characteristics, its geological features and its climate from space have provided new data layers with spatial and temporal resolutions relevant to landscape-scale habitat characteristics and ecological processes [194, 195]. The landscape, vegetation, and ecosystem attributes derived from the applied remote sensing data contribute significantly to defining habitat characteristics and help discern patterns and gradients that may exist even within seemingly homogeneous environments.

The use of RS may involve various degree of complexity. The simplest case is when larval habitats are large enough to be directly identified within spatial resolution of remote sensors as, e.g., in Wood et al [55] study from irrigated rice in northern and central California. This study [55] provided a model of rice field mosquito population dynamics using spectral and spatial information. Analysis of field data revealed that rice fields with rapid early season vegetation canopy development, located near livestock pastures (i.e. bloodmeal sources), had greater mosquito larval populations than fields with more slowly developing vegetation canopies located further from pastures. Remote sensing reflectance measurements of early season rice canopy development and GIS measurements of distance to livestock pasture were combined to distinguish between high and low mosquito-producing rice fields. These distinctions were made with $90 \%$ accuracy nearly two months before anopheline larval populations peaked.

A more complex approach is needed in situations where larval habitats are spatially below the detection limit of RS data. As an example, a hierarchical approach was used to link larval habitat-types with larger land cover units in an integrated RS, GIS and field study in the Pacific coastal plain of Chiapas, Mexico [57]. Using this approach, villages with high vs. low risk for malaria transmission were identified and it was demonstrated that remote sensing-based models generated for one area can be used successfully in another, comparable area [59, 60]. Similarly, RS generated maps of larval habitats in Madagascar rice fields and urban areas were used for predictions of adult densities and definitions of areas that may require indoor insecticide spraying [196, 197]. The landscape determinants of anopheline mosquito larval habitats in Kenya highlands and lowlands and their temporal changes were assessed by Mushinzimana et al. [198], Jacob et al [199], Munga et al [200], Mutuku et al [201], from elsewhere in Central and west Africa by Dambach [193] and Clennon et al [202], and from Malaysia by Ahmad et al [203]. The use of RS as a predictive tool to locate larval habitats has not always been successful as demonstrated by Achee et al [204]. Their results indicated that remotely sensed land cover is not a valuable indicator of the location in which An. darlingi larval habitats will form. High-resolution satellite imagery could be used to detect homes along river systems and potentially predict general areas at risk for An. darlingi breeding habitat formation based on distances from houses to waterways (Figure 3). The basic idea behind the remotely sensed assessment of larval habitats is to define environmental parameters that can be used to identify areas with increased risk of malaria transmission [193]. Yet, as already stated by 
Roberts et al [205], the successful use of RS and GIS technologies to predict potential or actual malaria trouble spots is dependent on clear understandings of environmental factors that determine the presence of malaria vectors.

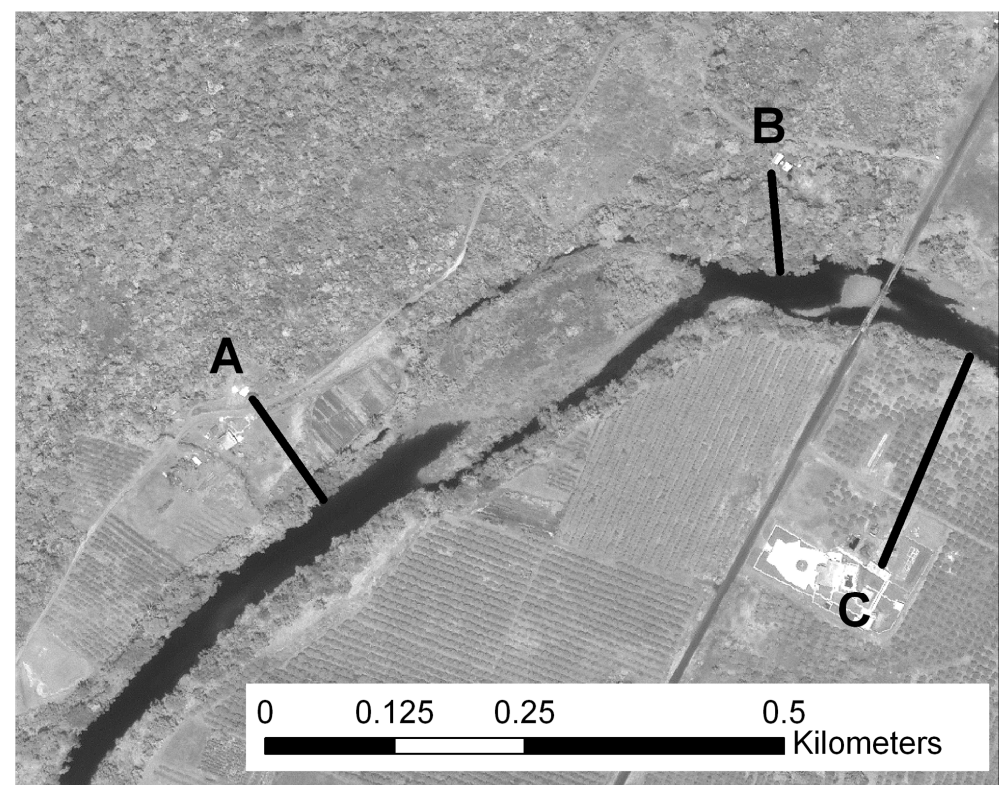

Figure 3. IKONOS $1 \mathrm{~m}$-resolution panchromatic image showing three houses (A-C) along a section of the Sibun River. Distance from the river to houses (black lines) was predictive for presence and abundance of An. darlingi, the primary malaria vector in Belize.

\subsection{Ecological niche models}

Populations of mosquito larvae are ideally suited to GIS and remote sensing applications due to their close association with their microenvironment. Specifically, larval mosquitoes have three distinct ecological characteristics that are directly related to predictive risk-modeling: 1) specific habitat preferences, 2) microclimate requirements and 3) vegetation-dependent associations to include plant height and density. Spatial-temporal interactions of mosquito larvae with their natural environment are critical to understanding the risk of contact between the vectors and their human hosts. Due to the fact that mosquitoes spend a substantial portion of their life cycle in the larval stage, population structure and vector survival is greatly influenced by the environmental surroundings. One area that is increasingly being applied to disease ecology which takes advantage of these environmental associations is the use ecological niche models [206]. An ecological niche model is an estimate of the distribution of a species and requires two input data sets: the known locations of a species and environmental data in an image format (such as larval habitats, climate data, elevation data, land cover, etc.). The ecological niche modeling program examines the environmental data at the locations where 
the species occurs to infer the environmental requirements of the species across a much larger area. The requirements of the species are then used to create a map of the predicted distribution of the species. Any species affected by environmental conditions such as climate can be modeled including disease vectors, disease hosts and pathogens. Models of monthly predictions of dengue fever in Mexico have been created based on mosquito activity [207]. Niche models of malaria vectors in the An. gambiae complex have been developed for under-sampled regions of Africa [208]. The benefit of niche modeling is the development of maps showing predicted distribution of an organism based on current and projected vector ecology and environmental data.

\section{Human impact land use/global change}

Natural ecosystems throughout the world are being severely altered by human intervention. Population pressure results in transformation of natural ecosystems to agriculture, construction of roads and hydroelectric dams, irrigation projects, open pit mines, and uncontrolled human colonization $[209,210]$. Anthropogenic modification of the ecosystems also contributes to global climate change represented by an increase in temperature and accompanied by extremes of the hydrologic cycle (e.g., floods and droughts) [211, 212]. The global rate of tropical deforestation continues with nearly $2 \%$ to $3 \%$ of global forests lost each year and land use change for agriculture represents the largest driver of land cover change across the earth $[85,209,213]$. Arthropod vectors in general, and insect vectors in particular are very sensitive to their environment, which determines their presence, development and behavior. As a consequence, climatic, as well as landscape and land cover factors greatly influence the spatial distribution of vectors and the diseases they transmit [214].

Mosquitoes are among the most sensitive insects to environmental change; their survival, density, and distribution are dramatically influenced by small changes in environmental conditions, such as temperature, humidity, and the availability of suitable larval habitats [48, 88, 215-219]. All these changes can alter the incidence, seasonality and intensity of transmission, and geographic range of diseases such as malaria. Changes in the distribution of malaria cases and intensities of malaria transmission have been documented by many historical examples. As described by Hackett [220], malaria increased in Malaya as jungle was cleared for rubber plantations. Where forest was removed the sun penetrated and populations of Anopheles maculatus mosquitoes proliferated, greatly increasing the incidence of human malaria. The better we are able to assess and explain the distribution and dynamics of vector species in relation to fluctuations in their environments, the more accurate prediction can be made of malaria in the context of ongoing environmental change [221, 222]. This will allow us to evaluate the risks associated with current practices, better explain the patterns of increasing and decreasing disease, better identify measures to mitigate the likelihood and impact of disease emergence, and eventually improve its control [213]. Below are specific examples of changes related to important human activities. 


\subsection{Deforestation}

Deforestation is one of the most important factors driving emerging and re-emerging infectious diseases. Through the process of clearing forests and subsequent agricultural development, deforestation changes almost every attribute of local ecosystems such as microclimate, soil, and aquatic conditions, and most significantly, the ecology of local flora and fauna, including human disease vectors. Numerous country and area studies have described the influence of deforestation and subsequent land use on the density of local mosquito vectors [223]. One of the most thorough evaluations of the impact of deforestation combined with the prediction of future changes has been presented by Yasuoka and Levins [224] who conducted a metaanalysis of 60 published studies of changes in ecology of 31 anopheline species and malaria incidence as a consequence of deforestation. In comprehensive tables they summarized density changes by land cover, and for larval habitats the niche-width and sun-preference indices of each species. The conclusion was that mechanisms linking deforestation and agricultural development with mosquito ecology and malaria epidemiology are extremely complex. The impacts of deforestation on mosquito density and malaria incidence are influenced by both the nature of the agricultural development and the ecological characteristics of the local vector mosquitoes. Some species were directly affected by deforestation, some favored or could adapt to the different environmental conditions, and some invaded and/or replaced other species in the process of development and cultivation. The results of the statistical analyses showed that deforestation and agricultural development are favorable for sun-loving species, allowing them to increase in or invade deforested areas where water bodies become exposed to sunlight.

As a specific example of the complexity of a malaria vector to deforestation we present the case of An. darlingi in the Amazon region. Vittor et al [225] examined the larval breeding habitat of a major South American malaria vector, An. darlingi, in areas with varying degrees of ecologic alteration in the Peruvian Amazon and concluded that deforestation and associated ecologic alterations are conducive to An. darlingi larval presence, and thereby increase malaria risk. According to Barros et al [82], deforestation and human presence creates a new habitat, a forest fringe ecosystem, by promoting three changes in An. darlingi bionomics: (i) increasing contact with humans; (ii) increasing the number of microdams (small river obstruction causing the accumulation of debris), which increases the number of potential larval habitats as well as the breeding season; and (iii) reducing the number of shaded breeding sites in a given geographical area, which results in a concentration of larvae in remaining shaded areas. The ideal breeding site occurs in the forest fringe, where the three factors, shade, microdams and human blood meals, are located close to each other.

Environmental changes caused by deforestation often lead to vector replacement (for examples referenced in older papers see Service [136]). Conn et al. [226] conducted entomological surveys in malaria areas of Macapá, northeastern Amazonia, and found An. marajoara replacing An. darlingi as the primary vector. It is hypothesized that the observed change in mosquito population densities was caused by deforestation for agriculture that resulted in newly created ground pools favoring An. marajoara larvae. For many regions in the Amazon Basin, populations of An. darlingi have increased because road construction in the forest has considerably expanded the breeding sites-large areas of neutral, partially shaded and unpolluted water. 
These characteristics also attract human inhabitants. Subsequently, clearing of forests and water pollution reduce the suitability of these for An. darlingi breeding. However, these sites, and newly created ponds for agricultural use, attract other mosquito species such as $A n$. marajoara. In addition, humans have colonized land near extensive marshy areas, another preferred breeding habitat of An. marajoara.

\subsection{Dam construction}

Water reservoirs have long been recognized to be a risk factor for malaria transmission [227-231]. Hydroelectric or irrigation dam construction increases the habitat availability by the formation of lakes. Shallow parts of these lakes are typically overgrown with macrophytes that provide excellent breeding sites for anopheline mosquitoes [227]. However, compared to the number of studies on land use change due to deforestation and agricultural expansion, research related to the entomological and ecological determinants of the rising malaria burden in the vicinity of large dams is rather limited [232]. There are historical examples, such as that of Tennessee Valley Authority ([35], see also p.3) of well executed environmental management measures to control malaria vectors [21, 35]. These successfully executed environmental measures can be adapted to control malaria associated with dam construction in sub-Saharan Africa and elsewhere in malaria endemic regions. Construction of new reservoirs under the tropical, sub-humid climatic conditions should therefore be accompanied by entomologic studies to predict the risk of malaria epidemics [233]. Keiser et al [231] calls for institutionalization of health impact assessments for future water development projects analogous to environmental impact assessments as well as the employment of monitoring and surveillance systems that would facilitate systematic evaluation of the impact of these ecosystem interventions over time. The reality is that more dams will be built and thus mitigation strategies to alleviate potential negative health effects are mandatory to reduce the current burden of malaria in settings near irrigation or dam projects.

\subsection{Wetland destruction}

Draining wetlands has been extensively practiced and promoted as the easiest solution to localized public health threats posed by malaria vectors [21, 234]. Unfortunately, this practice has not always worked. Among many cases of increasing malaria transmission after destruction of natural wetlands are the examples from African papyrus swamps [64]. As stated already by Goma [32, 235] and confirmed recently by others [72, 88, 236], the interior of a papyrus swamp is unsuitable for anophelines, while the swamp periphery and cultivation of natural swamps provides productive larval habitats for An. gambiae and consequently, increase the risks of malaria transmission to the human population. Many natural wetlands have been destroyed and changed to brick-making pits - the most abundant habitat type containing An. gambiae larvae in Africa [237].

What has not been taken into account when manipulating wetlands for health benefits is the loss of valuable ecosystem services provided by these wetlands, such as water purification, flood control, or provision of food and fiber, and their contributions to human health. This aspect was emphasized by the 2008 Conference of the Contracting Parties to the Ramsar 
Convention on Wetlands, whose resolution stated among others: "Those concerned with wetland conservation and management should encourage new and ongoing research regarding the links between wetlands and human health and to bring information on the scientifically proven contributions that functioning wetland ecosystems make to good health to the attention of national ministries and agencies responsible for health, sanitation, and water supply. The human health sector, and all relevant stakeholders should collaborate in assessing the consequences of wetland management linked with human health, and vice versa the consequences for the ecological character of wetlands of current practices which seek to maintain or improve human health, including the identification of appropriate trade-offs in decisionmaking."

\subsection{Wetland creation and restoration}

In addition to rice fields, which are the most extensive human made wetlands and their significance as larval habitat has been already described previously, the use of constructed wetlands for wastewater treatment is expanding [236, 238, 239]. Constructed wetland technology has broad applications for the treatment of many types of wastewaters and provides an ecological approach to mitigate the release of nutrients and toxic materials into the environment [240]. However, design features, maintenance activities and the characteristics of the wastewater undergoing treatment contribute differentially to potential levels of mosquito production and, consequently, to threats to human and animal health from mosquito-borne pathogens. Nutrients (nitrogen and phosphorus), and the configuration and maintenance of emergent vegetation can have strong effects on mosquito production. As loading rates of organic matter and nutrients decline, the diversity of mosquitoes produced by treatment wetlands tends to increase and the relative abundance of Anopheles species increases in temperate man-made wetlands [239, 241]. A proper design, e.g. subsurface rather than surface flow or flow-through rather than pond-type wetland [242] can help local mosquito problems. Surface-flow wetlands can also be designed to minimize mosquito breeding by increasing macro-invertebrate predators [243]. Greenway [243] concluded that a marsh with a diversity of macrophytes appears optimal for macro-invertebrate biodiversity and the control of mosquito larvae by predation. The key to mosquito management is to ensure a well-balanced ecosystem supporting a diversity of aquatic organisms [240]. A general conclusion from those areas that contain both treatment wetlands and unimpacted natural wetlands is that adequately designed and appropriately managed treatment wetlands do not pose any greater mosquito threat than the existing natural wetlands [244].

To compensate for a large loss of wetlands in the past, we are now witnessing many projects attempting to restore, rehabilitate, or create various types of wetland habitats. The resulting restored wetland areas provide flood control, improve water quality, and provide habitat for wildlife, especially bird species. However, they create great mosquito habitat and only a few restoration project address this issue properly [234] and there is a need for a better coordination between wetland restoration design and management and mosquito larval management. 


\subsection{Eutrophication}

Freshwaters are among the most extensively and rapidly altered ecosystems on the planet [213]. Increased use of fertilizers in agriculture and destruction of natural buffer zones leads to runoff of excessive nutrients, specifically nitrogen and phosphorus to lakes, rivers and reservoirs [245-250]. Nutrient increase is generally responsible for plant production resulting in potential changes in other trophic levels. Several studies have shown positive correlations between concentrations of inorganic nutrients in surface waters and larval abundance for Anopheles [43, 251]. Nutrient enriched waters are easily invaded by aggressive aquatic weeds such as water hyacinth (Eichhornia crassipes), which are known to be very productive anopheline habitats [37, 44, 252].

The authors' research in Belize [56, 86] provided data in support of the hypothesis that eutrophication causes changes in freshwater communities. The Central American country of Belize contains large wetland areas that used to be dominated by phosphorus limited sparse macrophyte communities interspersed with floating mats of cyanobacteria - a typical An. albimanus habitat (Figure 4).

\section{SPECIES REPLACEMENT AND LARVAL HABITAT CHANGE}

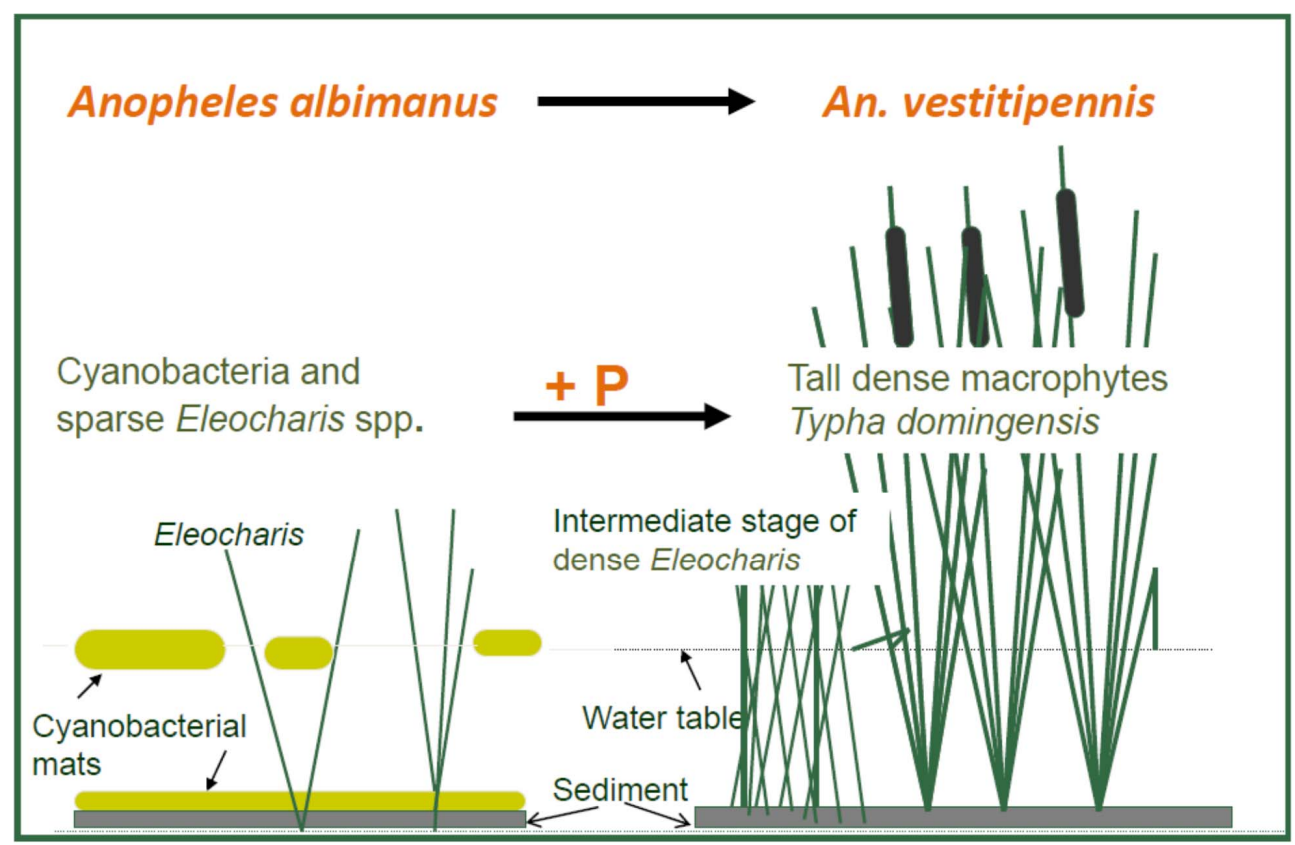

Figure 4. Schematic representation of the change of plant communities in marshes of Belize caused by increased eutrophication by phosphorus. This change is accompanied by the replacement of An. albimanus habitat with An. vestitipennis habitat. 
Anthropogenically mediated P enrichment of wetland plant communities through introduction of fertilizer runoff from expanding sugar cane fields is causing a switch from sparse macrophytes to tall dense macrophytes represented mostly by Typha domingensis. Tall dense macrophytes provide favorable habitat for An. vestitipennis, which appears to be a more efficient vector of malaria. Thus human-caused nutrient enrichment of marshes may lead to increased risk of malaria transmission in human settlements in proximity to the impacted marshes.

\subsection{Temperature and precipitation changes}

Malaria transmission is very sensitive to both temperature and precipitation, which makes the issue of change in risk due to past and projected warming trends one of the most important climate change-health questions to follow [253, 254]. Large malaria epidemics in the East African highlands during the mid and late 1990s initiated research on the role that global warming might have on malaria transmission. Historically, these highlands have been used as a shelter against malaria because malaria has been naturally absent due to conditions that limit the biology of the parasite [255]. Several authors proposed that spread of malaria into areas that rarely saw malaria transmission could be related to the impacts of small increases in temperature [253, 256]. The issue became hotly debated [255]. Recently, Chaves et al [257] assessed conclusions from both sides of the argument and found that evidence for the role of climate is robust but they also found a large heterogeneity in malaria trends. They argued that over-emphasizing the importance of climate is misleading for setting a research agenda to understand climate change impacts on emerging malaria patterns. The global change is expected to influence rainfall patterns both seasonal rainfall totals and inter-annual variability in malaria endemic regions, and these events will impact larval habitats availability and thus mosquito population dynamics [258].

\subsection{Sea level rise}

Along with warming temperatures, any increase in sea levels will affect the extent of saline (>30 ppt) or brackish (0.5-30 ppt) water bodies in coastal areas. These include coastal estuaries, lagoons, marshes and mangroves [106]. An expansion of brackish and saline water bodies in coastal areas, associated with rising sea levels, can increase densities of salinity-tolerant vector mosquitoes and lead to the adaptation of freshwater vectors to breed in brackish and saline waters. Higher vector densities can increase transmission of vector-borne infectious diseases in coastal localities, which can then spread to other areas [106].

The consequences of human-induced ecological changes provide another set of examples. Large-scale shrimp farming in the Mekong delta of Vietnam locally increased the density of An. sundaicus [259]. The greater availability of brackish water bodies can also lead to freshwater breeding mosquitoes such as An. stephensi and An. culicifacies getting adapted to breed in brackish waters as was observed immediately after the 2004 tsunami in India [260] and some years later in eastern Sri Lanka [261]. 


\subsection{Replacability and adaptability}

As already indicated by a few examples in the above text, a change in ecology of a region whether due natural factors or human impact can lead to changes in the quality and quantity of larval habitats. This often leads to changes in mosquito population dynamics and species composition [262]. The original anopheline species can be replaced by species better adapted to new conditions or they can adapt themselves. Mosquito species distributed over broad geographic ranges are more likely to have greater habitat diversity than species distributed over a small range [263] and thus their adaptability can be higher. Except for a few examples, our knowledge on the species adaptability is quite limited. But since at least some species are able to adapt to different environmental conditions, an effort needs to be made to obtain data on anopheline population dynamics before, during, and after ecologic alterations. Furthermore, the long-term effectiveness of any control strategy will depend on whether vectors respond to the evolutionary selection pressure created by intervention [22]. For example, mosquitoes may respond by phenotypic plasticity, or by evolving traits such as insecticide resistance or behavioral avoidance.

\section{Implication for vector control}

Malaria vector control targeting the larval stages of mosquitoes was applied successfully against many species of Anopheles in malarious countries until the mid-20 $0^{\text {th }}$ Century $[3,8$, 264-266]. Since the introduction of DDT in the 1940s and the associated development of indoor residual spraying (IRS), which usually has a more powerful impact on vectorial capacity than larval control, the focus of malaria prevention programs shifted to the control of adult vectors $[8,267]$. However, when it became clear that this strategy is not working (Service 1983), an integrated disease management approach including control of larval stages of malaria vectors, i.e., Integrated Vector Management (IVM) began to be reconsidered [21, 268]. A great step in that direction was made by Keiser et al [264] who provided a systematic review and a metaanalysis of malaria control programs, emphasizing environmental management as their main feature. Most of the 40 studies (85\%) were implemented before the Global Malaria Eradication Campaign (1955-69). The authors concluded that malaria control programs that emphasize environmental management are highly effective in reducing malaria. Lessons learned from these past successful programs can guide sound and sustainable malaria control approaches and strategies. The conclusions of Keiser's et al [231] meta-analysis of past control strategies are in agreement with recently developed malaria transmission models showing that substantial reductions of the entomological inoculation rate are possible when an integrated malaria control program with multiple interventions (e.g., environmental management tools) implemented simultaneously is used [269, 270].

The larval source management (LSM) also termed Environmental management that has been successfully used to control mosquitoes in many developed countries (US, Brazil, Canada) is recently becoming an integral component of malaria control methods in Africa [271]. LSM includes: (1) habitat (or environmental) modification, (2) habitat (environmental) manipulation, (3) biological control and (4) larviciding [236, 264, 271]. Habitat modification is designed 
to prevent, eliminate, or reduce vector habitat and it involves a permanent change of land and water, including landscaping, drainage of surface water, land reclamation and filling but also coverage of large water storage containers, wells and other potential breeding sites. Habitat manipulation refers to activities that reduce larval habitats of the vector mosquito through temporary changes to the aquatic environment in which larvae develop. It is a recurrent activity, such as water-level manipulation, which includes measures such as flushing, drain clearance, shading or exposing habitats to the sun depending on the ecology of the local vector. It may include planting water-intensive tree species such as Eucalyptus robusta to reduce standing water in marshy areas. The best strategies are those that are adapted to local vector ecology, epidemiology and resources, guided by operational research and subject to routine monitoring and evaluation [22, 272]. Bond's et al [122, 123] studies can serve as an example of habitat manipulation. They report on how manual algal removal from breeding pools along a river in southern Mexico significantly reduced both larval and adult densities of An. pseudopunctipennis. In a follow up study, the abundance of An. pseudopunctipennis larvae + pupae was dramatically reduced by this treatment and remained depressed for two to three months. Algal extraction did not reduce the overall abundance of aquatic insects in river pools. Biological control of mosquitoes refers to the introduction of natural enemies into aquatic habitats; these are predatory fish or invertebrates, parasites or disease organisms (see the predator section). Bacillus thuringiensis israelensis (Bti) and Bacillus sphaericus (Bs) are bacterial species reported to be effective against mosquitoes, and have been widely studied and used as biolarvicides $[266,273,274]$. Recently, researchers have focused on the resident microbiota of insect vectors that can potentially impede transmission of human pathogens. These microbes may prove effective agents for manipulating the vector competence of malaria and other important human pathogens [275-278]. Biological control agents should be evaluated with respect to their climatic compatibility and their capability to maintain very close interactions with target populations [155].

\section{What next?}

Almost every paper that we reviewed for this chapter ends up with the call for more information on larval stages of malaria vectors, in order to enable a better vector control and more accurate predictions of vector response to changing environment. It is (finally!) becoming clear that understanding the ecology and evolution of mosquito vectors needs to complement epidemiology, genetics and molecular biology in solving malaria problems. Several review papers provide good suggestions for future directions in vector ecology research (see, e.g., Table 2 in Chaves and Koenraadt [255] and Box 3 in Ferguson et al [22]). As stated in the preceding text, almost any factor defining a larval habitat can change as a result of direct human modification (deforestation, agricultural practices, eutrophication) and/or indirectly caused environmental change (temperature, precipitation). In addition, new habitats can be created. All these changes can and will impact the basic environmental determinants of larval habitats - food availability, refuge, predator presence. There are indications that some species will be able to adapt, some will be replaced by other species, and some anophelines that have not traditionally been regarded as vectors may become important ones. 
In the context of ecosystem change whether due to nutrient, temperature, precipitation, salinity or vegetation changes, there is a strong need for studies on adaptability of different anopheline species to new conditions. The majority of these studies would be best executed as manipulative field or semi-field experiments focused not only on changing characteristics of species performance but also on interactions with other species (both competition and predation). To be able to accomplish these types of experiments, systems of enclosed, pathogen-free, semifield mesocosms in which vector populations can be experimentally manipulated will have to be established within environmentally realistic, contained semi-field settings. See, e.g., $\mathrm{Ng}^{\prime}$ habi et al [11] semi-field system of large, netting-enclosed mesocosms, in which vectors can fly freely, feed on natural plant and vertebrate host sources, and access realistic resting and oviposition sites. Ideally, systems of these experimental mesocosms should be established along environmental (temperature, precipitation) gradients or with the capability to experimentally manipulate these variables so that we can conduct the experiments focused on species response to changing environments.

In addition, there is an ongoing need for regular monitoring and good quality long-term dataset on species distributions. High resolution satellite data enable more detailed observations on vegetation changes and regional distribution of precipitations and temperature, which all can results and result in better risk prediction maps [193]. In order to include a temporal component to the risk models, a network of longitudinal population monitoring sites for vector development needs to be established. The ecological niche models [206, 279] mentioned above will undoubtedly play increasingly important role in predictions of disease outbreaks.

\section{Acknowledgements}

We thank Stephanie Castle for technical help. Parts of the research referred to in the chapter was supported by the NIH-NSF Ecology of Infectious Diseases program, Grant \# R01 AI49726, "Environmental Determinants of Malaria in Belize".

\section{Author details}

Eliška Rejmánková1 ${ }^{*}$, John Grieco ${ }^{2}$, Nicole Achee $^{2}$ and Donald R. Roberts²,3

*Address all correspondence to: erejmankova@ucdavis.edu

1 Department of Environmental Science and Policy, University of California, Davis, USA

2 Department of Preventive Medicine \& Biometrics, Uniformed Services University of the Health Sciences, Bethesda, USA

3 Retired, Professor Emeritus, present address: Clifton Forge, VA, USA 


\section{References}

[1] Zimmerman RH. Ecology of malaria vectors in the America and future direction. Memorias Do Instituto Oswaldo Cruz. 1992; 87 371-83.

[2] Gubler DJ. Resurgent vector-borne diseases as a global health problem. Emerging Infectious Diseases. 1998; 4(3) 442-50.

[3] Townson H, Nathan MB, Zaim M, Guillet P, Manga L, Bos R, et al. Exploiting the potential of vector control for disease prevention. Bulletin of the World Health Organization. 2005; 83(12) 942-7.

[4] Zanetti AR, Zappa A. Emerging and re-emerging infections at the turn of the millennium. Haemophilia. 2010; 16 7-12.

[5] Eckhoff PA. A malaria transmission-directed model of mosquito life cycle and ecology. Malaria Journal. 2011; 10, 303.

[6] Rubbo MJ, Lanterman JL, Falco RC, Daniels TJ. The influence of amphibians on mosquitoes in seasonal pools: can wetlands protection help to minimize disease risk? Wetlands. 2011; 31(4) 799-804.

[7] da Silva-Nunes M, Moreno M, Conn JE, Gamboa D, Abeles S, Vinetz JM, et al. Amazonian malaria: Asymptomatic human reservoirs, diagnostic challenges, environmentally driven changes in mosquito vector populations, and the mandate for sustainable control strategies. Acta Tropica. 2012; 121(3) 281-91.

[8] Walker K, Lynch M. Contributions of Anopheles larval control to malaria suppression in tropical Africa: review of achievements and potential. Medical and Veterinary Entomology. 2007; 21(1) 2-21.

[9] Gimnig JE, Ombok M, Kamau L, Hawley WA. Characteristics of larval anopheline (Diptera : Culicidae) habitats in western Kenya. Journal of Medical Entomology. $2001 ; 38(2)$ 282-8.

[10] Gimnig JE, Ombok M, Otieno S, Kaufman MG, Vulule JM, Walker ED. Density-dependent development of Anopheles gambiae (Diptera : Culicidae) larvae in artificial habitats. Journal of Medical Entomology. 2002; 39(1) 162-72.

[11] Ng'habi KR, Mwasheshi D, Knols BGJ, Ferguson HM. Establishment of a self-propagating population of the African malaria vector Anopheles arabiensis under semi-field conditions. Malaria Journal. 2010; 9, 356.

[12] Hiwat H, Bretas G. Ecology of Anopheles darlingi Root with respect to vector importance: a review. Parasites \& Vectors. 2011; 4, 177.

[13] Clements A. The Biology of Mosquitoes. Volume 1. Development, nutrition and reproduction. London: Chapman \& Hall; 1992. 
[14] Clements A. The Biology of Mosquitoes. Volume 2. Sensory reception and behavior. Wallingford: Cabi Publishing; 1999.

[15] Clements A. The Biology of Mosquitoes. Volume 3. Transmission of viruses and interactions with bacteria. Wallingford: Cabi Publishing; 2012.

[16] Fournet F, Cussac M, Ouari A, Meyer PE, Toe HK, Gouagna LC, et al. Diversity in anopheline larval habitats and adult composition during the dry and wet seasons in Ouagadougou (Burkina Faso). Malaria Journal. 2010; 978.

[17] Sinka ME, Bangs MJ, Manguin S, Rubio-Palis Y, Chareonviriyaphap T, Coetzee M, et al. A global map of dominant malaria vectors. Parasites \& Vectors. 2012; 569.

[18] Bates M. Oviposition experiments with Anopheline mosquitoes. American Journal of Tropical Medicine and Hygiene. 1940; 20(4) 569-83.

[19] Merritt RW, Dadd RH, Walker ED. Feeding-behavior, natural food, and nutritional relationships of larval mosquitos. Annual Review of Entomology. 1992; 37 349-76.

[20] Killeen GF, Fillinger U, Kiche I, Gouagna LC, Knols BGJ. Eradication of Anopheles gambiae from Brazil: lessons for malaria control in Africa? Lancet Infectious Diseases. 2002; 2(10) 618-27.

[21] Kitron U, Spielman A. Suppression of transmission of malaria through source reduction - Antianopheline measures applied in Israel, the United-States, and Italy. Reviews of Infectious Diseases. 1989; 11(3) 391-406.

[22] Ferguson HM, Dornhaus A, Beeche A, Borgemeister C, Gottlieb M, Mulla MS, et al. Ecology: A prerequisite for malaria elimination and eradication. Plos Medicine. 2010; 7(8) e1000303.

[23] Service MW. Biological control of mosquitos - has it a future. Mosquito News. 1983; 43(2) 113-20.

[24] Laird M. The Natural History of Larval Mosquito Habitats. London: Academic; 1988. p. 555.

[25] Komp WHW. The occurrence of Anopheles darlingi. Root in British Honduras and Guatemala. Public Health Reports. 1940; 55(16) 693-4.

[26] Kumm HV, Ram LM. Observations on the Anopheles of the British Honduras. American Journal of Tropical Medicine and Hygiene. 1941; 21 559-66.

[27] Bertram DS. Mosquitoes of British Honduras, with some comments on malaria, and on arbovirus antibodies in man and equines. Transactions of the Royal Society of Tropical Medicine and Hygiene. 1971; 65(6) 742-62.

[28] Roberts DR, Chan O, Pecor J, Rejmankova E, Manguin S, Polanco J, et al. Preliminary observations on the changing roles of malaria vectors in southern Belize. Journal of the American Mosquito Control Association. 1993; 9(4) 456-9. 
[29] Muirhead-Thomson RC. Studies on the behaviour of Anopheles minimus. Part III. The influence of water temperature on the choice and suitability of the breeding place. Journal of the Malaria Institute of India. 1940; 3 323-48.

[30] Goma LKH. The productivity of various mosquito breeding places in the swamps of Uganda. Bulletin of Entomological Research. 1958; 49 437-48.

[31] Goma LKH. The swamp-breeding mosquitoes of Uganda: Records of larvae and their habitats. Bulletin of Entomological Research. 1960; 51 77-94.

[32] Goma LKH. Experimental breeding of Anopheles gambiae Giles in papyrus swamps. Nature. 1960; 187(4743) 1137-8.

[33] Howland LJ. Bionomical investigation of English mosquito larvae with special reference to their algal food. Journal of Ecology. 1930; 18 81-125.

[34] Bates M. The Natural History of Mosquitoes. New York: MacMillan; 1949.

[35] Authority TV. Malaria Control on Impounded Water. Washington DC: US Government Printing Office; 1947.

[36] Hinman EH. The role of bacteria in the nutrition of mosquito larvae - The growthstimulating factor. American Journal of Hygiene. 1933; 18(1) 224-36.

[37] Penfound WT, Earle TT. The biology of the water hyacinth. Ecological Monographs. 1948; 18(4) 447-72.

[38] Hess A, Hall T. The intersection line as a factor in anopheline ecology. The Journal of National Malaria Society. 1943; 2(2) 93-8.

[39] Hall TF. Influence of plants on anopheline breeding. American Journal of Tropical Medicine and Hygiene. 1972; 21(5) 787-94.

[40] Orr BK, Resh VH. Experimental test of the influence of aquatic macrophyte cover on the survival of Anopheles larvae. Journal of the American Mosquito Control Association. 1989; 5(4) 579-85.

[41] Savage HM, Rejmankova E, Arredondo-Jimenez JI, Roberts DR, Rodriguez MH. Limnological and botanical characterization of larval habitats for 2 primary malarial vectors, Anopheles albimanus and Anopheles pseudopunctipennis, in coastal areas of Chiapas State, Mexico. Journal of the American Mosquito Control Association. 1990; 6(4) 612-20.

[42] Rejmankova E, Roberts DR, Harbach RE, Pecor J, Peyton EL, Manguin S, et al. Environmental and regional determinants of Anopheles (Diptera, Culicidae) larval distribution in Belize, Central-America. Environmental Entomology. 1993; 22(5) 978-92.

[43] Rejmankova E, Savage HM, Rejmanek M, Arredondo-Jimenez JI, Roberts DR. Multivariate-analysis of relationships between habitats, environmental-factors and occur- 
rence of anopheline mosquito larvae Anopheles albimanus and A. pseudopunctipennis in southern Chiapas, Mexico. Journal of Applied Ecology. 1991; 28(3) 827-41.

[44] Rejmankova E, Savage HM, Rodriguez MH, Roberts DR, Rejmanek M. Aquatic vegetation as a basis for classification of Anopheles albimanus Weideman (Diptera, Culicidae) larval habitats. Environmental Entomology. 1992; 21(3) 598-603.

[45] Rozendaal JA. Observations on the distribution of anophelines in Surinam with particular reference to the malaria vector Anopheles darlingi. Memorias Do Instituto Oswaldo Cruz. 1990; 85(2) 221-34.

[46] Rozendaal JA. Relations between Anopheles darlingi breeding habitats, rainfall, river level and malaria transmission rates in the rain-forest of Surinam. Medical and Veterinary Entomology. 1992; 6(1) 16-22.

[47] Manguin S, Roberts DR, Andre RG, Rejmankova E, Hakre S. Characterization of Anopheles darlingi (Diptera: Culicidae) larval habitats in Belize, Central America. Journal of Medical Entomology. 1996; 33(2) 205-11.

[48] Grillet ME. Factors associated with distribution of Anopheles aquasalis and Anopheles oswaldoi (Diptera : Culicidae) in a malarious area, northeastern Venezuela. Journal of Medical Entomology. 2000; 37(2) 231-8.

[49] Rejmankova E, Rubio-Palis Y, Villegas L. Larval habitats of anopheline mosquitoes in the upper Orinoco, Venezuela. Journal of Vector Ecology. 1999; 24(2) 130-7.

[50] Rodriguez AD, Rodriguez MH, Meza RA, Hernandez JE, Rejmankova E, Savage HM, et al. Dynamics of population-densities and vegetation associations of Anopheles-albimanus larvae in a coastal area of southern Chiapas, Mexico. Journal of the American Mosquito Control Association. 1993; 9(1) 46-58.

[51] Rojas W, Penaranda F, Echavarria M. Strategies for malaria control in Colombia. Parasitology Today. 1992; 8(4) 141-4.

[52] Danis-Lozano R, Rodriguez MH, Arredondo-Jimenez JI, Hernandez Avila M, Mallorca C. Aquatic insects associated with Anopheles albimanus (Diptera: Culicidae) breeding sites in southern Mexico. Environmental Entomology. 1997; 26(4) 828-38.

[53] Vazquez-Martinez MG, Rodriguez MH, Arredondo-Jimenez JI, Mendez-Sanchez JD, Bond-Compean JG, Gold-Morgan M. Cyanobacteria associated with Anopheles albimanus (Diptera : Culicidae) larval habitats in southern Mexico. Journal of Medical Entomology. 2002; 39(6) 825-32.

[54] Torres-Estrada JJ, Meza-Alvarez RA, Cibrian-Tovar J, Rodriguez-Lopez MH, Arredondo-Jimenez JI, Cruz-Lopez L, et al. Vegetation-derived cues for the selection of oviposition substrates by Anopheles albimanus under laboratory conditions. Journal of the American Mosquito Control Association. 2005; 21(4) 344-9. 
[55] Wood B, Washino R, Beck L, Hibbard K, Pitcairn M, Roberts D, et al. Distinguishing high and low anopheline-producing rice fields using remote-sensing and GIS technologies. Preventive Veterinary Medicine. 1991; 11(3-4) 277-88.

[56] Pope K, Masuoka P, Rejmankova E, Grieco J, Johnson S, Roberts D. Mosquito habitats, land use, and malaria risk in Belize from satellite imagery. Ecological Applications. 2005; 15(4) 1223-32.

[57] Pope KO, Rejmankova E, Savage HM, Arredondo-Jimenez JI, Rodriguez MH, Roberts DR. Remote-sensing of tropical wetlands for malaria control in Chiapas, Mexico. Ecological Applications. 1994; 4(1) 81-90.

[58] Roberts DR, Rodriguez MH. The environment, remote-sensing, and malaria control. Disease in Evolution: Global Changes and Emergence of Infectious Diseases. 1994; 740 396-402.

[59] Beck LR, Rodriguez MH, Dister SW, Rodriguez AD, Rejmankova E, Ulloa A, et al. Remote-sensing as a landscape epidemiologic tool to identify villages at high-risk for malaria transmission. American Journal of Tropical Medicine and Hygiene. 1994; 51(3) 271-80.

[60] Beck LR, Rodriguez MH, Dister SW, Rodriguez AD, Washino RK, Roberts DR, et al. Assessment of a remote sensing-based model for predicting malaria transmission risk in villages of Chiapas, Mexico. American Journal of Tropical Medicine and Hygiene. 1997; 56(1) 99-106.

[61] Sinka ME, Bangs MJ, Manguin S, Coetzee M, Mbogo CM, Hemingway J, et al. The dominant Anopheles vectors of human malaria in Africa, Europe and the Middle East: occurrence data, distribution maps and bionomic precis. Parasites \& Vectors. 2010; 3 117.

[62] Sinka ME, Rubio-Palis Y, Manguin S, Patil AP, Temperley WH, Gething PW, et al. The dominant Anopheles vectors of human malaria in the Americas: occurrence data, distribution maps and bionomic precis. Parasites \& Vectors. 2010; 372.

[63] Sinka ME, Bangs MJ, Manguin S, Chareonviriyaphap T, Patil AP, Temperley WH, et al. The dominant Anopheles vectors of human malaria in the Asia-Pacific region: occurrence data, distribution maps and bionomic precis. Parasites \& Vectors. 2011; 489.

[64] Mouchet J, Manguin S, Sircoulon J, Laventure S, Faye O, Onapa AW, et al. Evolution of malaria in Africa for the past 40 years: Impact of climatic and human factors. Journal of the American Mosquito Control Association. 1998; 14(2) 121-30.

[65] Haddow AJ. Measurements of temperature and light in artificial pools with reference to the larval habitat of Anopheles (Myzomyia) gambiae Giles and A. (M.) funestus Giles. Bulletin of Entomological Research. 1943; 3489.

[66] Orr BK, Resh VH. Influence of Myriophyllum aquaticum cover on Anopheles mosquito abundance, oviposition, and larval microhabitat. Oecologia. 1992; 90(4) 474-82. 
[67] Rejmankova E, Roberts DR, Manguin S, Pope KO, Komarek J, Post RA. Anopheles albimanus (Diptera: Culicidae) and cyanobacteria: An example of larval habitat selection. Environmental Entomology. 1996; 25(5) 1058-67.

[68] Wallace JR, Merritt RW. Influence of microclimate, food, and predation on Anopheles quadrimaculatus (Diptera : Culicidae) growth and development rates, survivorship, and adult size in a Michigan pond. Environmental Entomology. 1999; 28(2) 233-9.

[69] Mutero CM, Blank H, Konradsen F, van der Hoek W. Water management for controlling the breeding of Anopheles mosquitoes in rice irrigation schemes in Kenya. Acta Tropica. 2000; 76(3) 253-63.

[70] Koenraadt CJM, Majambere S, Hemerik L, Takken W. The effects of food and space on the occurrence of cannibalism and predation among larvae of Anopheles gambiae s.l. Entomologia Experimentalis Et Applicata. 2004; 112(2) 125-34.

[71] Koenraadt CJM, Paaijmans KP, Githeko AK, Knols BGJ, Takken W. Egg hatching, larval movement and larval survival of the malaria vector Anopheles gambiae in desiccating habitats. Malaria Journal. 2003; 220.

[72] Munga S, Minakawa N, Zhou GF, Barrack OAJ, Githeko AK, Yan GY. Effects of larval competitors and predators on oviposition site selection of Anopheles gambiae sensu stricto. Journal of Medical Entomology. 2006; 43(2) 221-4.

[73] Achee NL, Grieco JP, Andre RG, Roberts DR, Rejmankova E. Experimental evaluation of overhanging bamboo in Anopheles darlingi larval habitat selection in Belize, Central America. Journal of Vector Ecology. 2006; 31(1) 145-51.

[74] Grieco JP, Rejmankova E, Achee NL, Klein CN, Andre R, Roberts D. Habitat suitability for three species of Anopheles mosquitoes: Larval growth and survival in reciprocal placement experiments. Journal of Vector Ecology. 2007; 32(2) 176-87.

[75] Carlson JC, Dyer LA, Omlin FX, Beier JC. Diversity cascades and malaria vectors. Journal of Medical Entomology. 2009; 46(3) 460-4.

[76] Jarju LBS, Fillinger U, Green C, Louca V, Majambere S, Lindsay SW. Agriculture and the promotion of insect pests: rice cultivation in river floodplains and malaria vectors in The Gambia. Malaria Journal. 2009; 8170.

[77] Montoya-Lerma J, Solarte YA, Giraldo-Calderon GI, Quinones ML, Ruiz-Lopez F, Wilkerson RC, et al. Malaria vector species in Colombia - A review. Memorias Do Instituto Oswaldo Cruz. 2011; 106 223-38.

[78] Chase JM, Knight TM. Drought-induced mosquito outbreaks in wetlands. Ecology Letters. 2003; 6(11) 1017-24.

[79] Chase JM, Shulman RS. Wetland isolation facilitates larval mosquito density through the reduction of predators. Ecological Entomology. 2009; 34(6) 741-7. 
[80] Blaustein L, Ostfeld RS, Holt RD. A community-ecology framework for understanding vector and vector-borne disease dynamics. Israel Journal of Ecology \& Evolution. 2010; 56(3-4) 251-62.

[81] Paaijmans KP, Jacobs AFG, Takken W, Heusinkveld BG, Githeko AK, Dicke M, et al. Observations and model estimates of diurnal water temperature dynamics in mosquito breeding sites in western Kenya. Hydrological Processes. 2008; 22(24) 4789-801.

[82] Barros FSM, Arruda ME, Gurgel HC, Honorio NA. Spatial clustering and longitudinal variation of Anopheles darlingi (Diptera: Culicidae) larvae in a river of the Amazon: The importance of the forest fringe and of obstructions to flow in frontier malaria. Bulletin of Entomological Research. 2011; 101(6) 643-58.

[83] Bates M, De Zulueta J. The seasonal cycle of Anopheline mosquitoes in a pond in eastern Colombia. American Journal of Tropical Medicine. 1949; 29(1) 129-50.

[84] Washburn JO. Regulatory factors affecting larval mosquito populations in container and pool habitats - Implications for biological-control. Journal of the American Mosquito Control Association. 1995; 11(2) 279-83.

[85] Stresman GH. Beyond temperature and precipitation: Ecological risk factors that modify malaria transmission. Acta Tropica. 2010; 116(3) 167-72.

[86] Rejmankova E, Grieco J, Achee N, Masouka P, Pope K, Roberts D, et al. Freshwater community interactions and malaria. In: Collinge SK, Ray C, editors. Disease Ecology. Oxford: Oxford University Press; 2006.

[87] Bayoh MN, Lindsay SW. Temperature-related duration of aquatic stages of the Afrotropical malaria vector mosquito Anopheles gambiae in the laboratory. Medical and Veterinary Entomology. 2004; 18(2) 174-9.

[88] Wamae PM, Githeko AK, Menya DM, Takken W. Shading by napier grass reduces malaria vector larvae in natural habitats in Western Kenya highlands. Ecohealth. 2010; 7(4) 485-97.

[89] Ndenga BA, Simbauni JA, Mbugi JP, Githeko AK, Fillinger U. Productivity of malaria vectors from different habitat types in the western Kenya highlands. Plos One. $2011 ; 6(4)$ e19473.

[90] Lindblade KA, Walker ED, Onapa AW, Katungu J, Wilson ML. Land use change alters malaria transmission parameters by modifying temperature in a highland area of Uganda. Tropical Medicine \& International Health. 2000; 5(4) 263-74.

[91] Imbahale SS, Mweresa CK, Takken W, Mukabana WR. Development of environmental tools for anopheline larval control. Parasites \& Vectors. 2011; 4130.

[92] Fillinger U, Sombroek H, Majambere S, van Loon E, Takken W, Lindsay SW. Identifying the most productive breeding sites for malaria mosquitoes in The Gambia. Malaria Journal. 2009; 862. 
[93] Marten GG, Suarez MF, Astaeza R. An ecological survey of Anopheles albimanus larval habitats in Colombia. Journal of Vector Ecology. 1996; 21(2) 122-31.

[94] Pinault LL, Hunter FF. Characterization of larval habitats of Anopheles albimanus, Anopheles pseudopunctipennis, Anopheles punctimacula, and Anopheles oswaldoi s.l. populations in lowland and highland Ecuador. Journal of Vector Ecology. 2012; 37(1) 124-36.

[95] White GB. Anopheles bwambae sp-n, a malaria vector in the Semliki Valley, Uganda, and its relationships with other sibling species of the An. gambiae complex (Diptera, Culicidae). Systematic Entomology. 1985; 10(4) 501-22.

[96] Paaijmans KP, Blanford S, Bell AS, Blanford JI, Read AF, Thomas MB. Influence of climate on malaria transmission depends on daily temperature variation. Proceedings of the National Academy of Sciences of the United States of America. 2010; 107(34) 15135-9.

[97] Chahad-Ehlers S, Lozovei AL, Marques MD. Reproductive and post-embryonic daily rhythm patterns of the malaria vector Anopheles (Kerteszia) cruzii: Aspects of the life cycle. Chronobiology International. 2007; 24(2) 289-304.

[98] Obsomer V, Defourny P, Coosemans M. The Anopheles dirus complex: spatial distribution and environmental drivers. Malaria Journal. 2007; 626.

[99] Bugoro H, Hii J, Russell TL, Cooper RD, Chan BKK, Iro'ofa C, et al. Influence of environmental factors on the abundance of Anopheles farauti larvae in large brackish water streams in Northern Guadalcanal, Solomon Islands. Malaria Journal. 2011; 10262.

[100] Surendran SN, Jude PJ, Ramasamy R. Variations in salinity tolerance of malaria vectors of the Anopheles subpictus complex in Sri Lanka and the implications for malaria transmission. Parasites \& Vectors. 2011; 4117.

[101] Dusfour I, Harbach RE, Manguin S. Bionomics and systematics of the oriental Anopheles sundaicus complex in relation to malaria transmission and vector control. American Journal of Tropical Medicine and Hygiene. 2004; 71(4) 518-24.

[102] Berti J, Navarro-Bueno E, Zoppi E, Gordon E, Delgado L. Estacionalidad de la densidad larval del mosquito Anopheles aquasalis (Diptera: Culicidae) y otros insectos asociados a su habitat en Sucre, Venezuela. Revista de Biologia Tropical. 2010; 58(2) 777-87.

[103] Smith KE, VanEkeris LA, Okech BA, Harvey WR, Linser PJ. Larval anopheline mosquito recta exhibit a dramatic change in localization patterns of ion transport proteins in response to shifting salinity: a comparison between anopheline and culicine larvae. Journal of Experimental Biology. 2008; 211(19) 3067-76.

[104] White BJ, Collins FH, Besansky NJ. Evolution of Anopheles gambiae in relation to humans and malaria. Annual Review of Ecology, Evolution, and Systematics, Vol 42. 2011; 42 111-32. 
[105] Krishnamoorthy K, Jambulingam P, Natarajan R, Shriram AN, Das PK, Sehgal SC. Altered environment and risk of malaria outbreak in South Andaman, Andaman \& Nicobar Islands, India affected by tsunami disaster. Malaria Journal. 2005; 432.

[106] Ramasamy R, Surendran SN. Possible impact of rising sea levels on vector-borne infectious diseases. BMC Infectious Diseases. 2011; 1118.

[107] Mitsch WJ, Gosselnk JG. Wetlands. 4th edition ed. Hoboken, New Jersey: John Wiley \& Sons, Inc.; 2007.

[108] Atieli HE, Zhou GF, Lee MC, Kweka EJ, Afrane Y, Mwanzo I, et al. Topography as a modifier of breeding habitats and concurrent vulnerability to malaria risk in the western Kenya highlands. Parasites \& Vectors. 2011; 4241.

[109] Paaijmans KP, Wandago MO, Githeko AK, Takken W. Unexpected high losses of Anopheles gambiae larvae due to rainfall. Plos One. 2007; 2(11) e1146.

[110] Charlwood JD, Braganca M. The effect of rainstorms on adult Anopheles funestus behavior and survival. Journal of Vector Ecology. 2012; 37(1) 252-6.

[111] Timms RM, Moss B. Prevention of growth of potentially dense phytoplankton populations by zooplankton grazing, in the presence of zooplanktivorous fish, in a shallow wetland ecosystem. Limnology and Oceanography. 1984; 29 472-86.

[112] Rejmankova E, Sirova D, Carlson E. Patterns of activities of root phosphomonoesterase and phosphodiesterase in wetland plants as a function of macrophyte species and ambient phosphorus regime. New Phytologist. [Article]. 2011; 190(4) 968-76.

[113] Ancona AH. Las Lemnaces y las larvas de los mosquitos. Anales del Instituto de Biología de México. 1930; 1(3) 3-37.

[114] Matheson R. The utilization of aquatic plants as aids in mosquito control. American Naturalist. 1930; 64 56-86.

[115] Balling SS, Resh VH. Seasonal pattern of pondweed standing crop and Anopheles occidentalis densities in Coyote Hills marsh. Proceedings of the California Mosquito Vector Control Association. 1985; 52 122-5.

[116] Rozeboom LE, Hess AD. The relation of the intersection line to the production of Anopheles quadrimaculatus. Journal of the National Malaria Society. 1944; 3 169-79.

[117] Walker ED, Merritt RW, Wotton RS. Analysis of the distribution and abundance of Anopheles-quadrimaculatus (Diptera, Culicidae) larvae in a marsh. Environmental Entomology. 1988; 17(6) 992-9.

[118] Collins JN, Resh VH. Measurements of temperature and light in artificial pools with reference to the larval habitat of Anopheles (Myzomyia) gambiae Giles and A. (M.) funestus Giles: California MVCA and University of California Mosquito Research Program1989. 
[119] Mutuku FM, Alaii JA, Bayoh MN, Gimnig JE, Vulule JM, Walker ED, et al. Distribution, description, and local knowledge of larval habitats of Anopheles gambiae s.l. in a village in western Kenya. American Journal of Tropical Medicine and Hygiene. 2006; 74(1) 44-53.

[120] Fernandez-Salas I, Roberts DR, Rodriguez MH, Marina-Fernandez CF. Bionomics of larval populations of Anopheles pseudopunctipennis in the Tapachula foothills area, southern Mexico. Journal of the American Mosquito Control Association. 1994; 10(4) 477-86.

[121] Rueda LM, Peyton EL, Manguin S. Anopheles (Anopheles) pseudopunctipennis Theobald (Diptera: Culicidae): Neotype designation and description. Journal of Medical Entomology. 2004; 41(1) 12-22.

[122] Bond JG, Rojas JC, Arredondo-Jimenez JI, Quiroz-Martinez H, Valle J, Williams T. Population control of the malaria vector Anopheles pseudopunctipennis by habitat manipulation. Proceedings of the Royal Society of London Series B-Biological Sciences. 2004; 271(1553) 2161-9.

[123] Bond JG, Quiroz-Martinez H, Rojas JC, Valle J, Ulloa A, Williams T. Impact of environmental manipulation for Anopheles pseudopunctipennis Theobald control on aquatic insect communities in southern Mexico. Journal of Vector Ecology. 2007; 32(1) 41-53.

[124] Manguin S, Roberts DR, Peyton EL, Rejmankova E, Pecor J. Characterization of Anopheles pseudopunctipennis larval habitats. Journal of the American Mosquito Control Association. 1996; 12(4) 619-26.

[125] Bond JG, Arredondo-Jimenez JI, Rodriguez MH, Quiroz-Martinez H, Williams T. Oviposition habitat selection for a predator refuge and food source in a mosquito. Ecological Entomology. 2005; 30(3) 255-63.

[126] Torres-Estrada JL, Meza-Alvarez RA, Cruz-Lopez L, Rodriguez MH, Arredondo-Jimenez JI. Attraction of gravid Anopheles pseudopunctipennis females to oviposition substrates by Spirogyra majuscula (Zygnematales : Zygnemataceae) algae under laboratory conditions. Journal of the American Mosquito Control Association. 2007; 23(1) $18-23$.

[127] Johnson HA. Occurence of Anopheles vestitipennis in Porto Rico. The American Journal of Tropical Medicine. 1925; 6(2) 153-5.

[128] Loyola EG, Arredondo-Jimenez I, Rodriguez MH, Brown DN, Vacamarin MA. Anopheles vestitipennis, the Probable Vector of Plasmodium vivax in the Lacandon Forest of Chiapas, Mexico. Transactions of the Royal Society of Tropical Medicine and Hygiene. 1991; 85(2) 171-4.

[129] Rejmankova E, Pope KO, Roberts DR, Lege MG, Andre R, Grieco J, et al. Characterization and detection of Anopheles vestitipennis and Anopheles punctimacula (Diptera : 
Culicidae) larval habitats in Belize with field survey and SPOT satellite imagery. Journal of Vector Ecology. 1998; 23(1) 74-88.

[130] Ulloa A, Rodriguez MH, Arredondo-Jimenez JI, Fernandez-Salas I. Biological variation in two Anopheles vestitipennis populations with different feeding preferences in southern Mexico. Journal of the American Mosquito Control Association. 2005; 21(4) $350-4$.

[131] Gratz NG. Emerging and resurging vector-borne diseases. Annual Review of Entomology. 1999; 44 51-75.

[132] Forattini OP, Kakitani I, Massad E, Marucci D. Studies on mosquitos (Diptera, Culicidae) and anthropic environment - 3-survey of adult stages at the rice irrigation system and the emergence of Anopheles albitarsis in South-Eastern, Brazil. Revista De Saude Publica. 1993; 27(5) 313-25.

[133] Mogi M, Okazawa T, Miyagi I, Sucharit S, Tumrasvin W, Deesin T, et al. Development and survival of anopheline immatures (Diptera, Culicidae) in rice fields in northern Thailand. Journal of Medical Entomology. 1986; 23(3) 244-50.

[134] Blaustein L. Larvivorous fishes fail to control mosquitos in experimental rice plots. Hydrobiologia. 1992; 232(3) 219-32.

[135] Mogi M, Miyagi I. Colonization of rice fields by mosquitoes (Diptera, Culicidae) and larvivorous predators in asynchronous rice cultivation areas in the Philippines. Journal of Medical Entomology. 1990; 27(4) 530-6.

[136] Service MW. Agricultural-development and arthropod-borne diseases - A review. Revista De Saude Publica. 1991; 25(3) 165-78.

[137] Ohba SY, Huynh TTT, Le LL, Ngoc HT, Hoang SL, Takagi M. Mosquitoes and their potential predators in rice agroecosystems of the Mekong Delta, southern Vietnam. Journal of the American Mosquito Control Association. 2011; 27(4) 384-92.

[138] Lacey LA, Lacey CM. The medical importance of riceland mosquitos and their control using alternatives to chemical insecticides. Journal of the American Mosquito Control Association. 1990; 1-93.

[139] Rejmankova E, Higashi R, Grieco J, Achee N, Roberts D. Volatile substances from larval habitats mediate species-specific oviposition in Anopheles mosquitoes. Journal of Medical Entomology. 2005; 42(2) 95-103.

[140] Lyimo EO, Takken W, Koella JC. Effect of rearing temperature and larval density on larval survival, age at pupation and adult size of Anopheles-gambiae. Entomologia Experimentalis Et Applicata. 1992; 63(3) 265-71.

[141] Koella JC, Lyimo EO. Variability in the relationship between weight and wing length of Anopheles gambiae (Diptera: Culicidae). Journal of Medical Entomology. 1996; 33(2) 261-4. 
[142] Peck GW, Walton WE. Effect of bacterial quality and density on growth and whole body stoichiometry of Culex quinquefasciatus and Culex tarsalis (Diptera: Culicidae). Journal of Medical Entomology. 2006; 43(1) 25-33.

[143] Cole JJ, Findlay S, Pace ML. Bacterial production in fresh and saltwater ecosystems a cross-system overview. Marine Ecology-Progress Series. 1988; 43(1-2) 1-10.

[144] Walker ED, Merritt RW. Bacterial enrichment in the surface microlayer of an Anopheles quadrimaculatus (Diptera, Culicidae) larval habitat. Journal of Medical Entomology. 1993; 30(6) 1050-2.

[145] Kaufman MG, Wanja E, Maknojia S, Bayoh MN, Vulule JM, Walker ED. Importance of algal biomass to growth and development of Anopheles gambiae larvae. Journal of Medical Entomology. 2006; 43(4) 669-76.

[146] Marten GG. Larvicidal algae. Journal of the American Mosquito Control Association. $2007 ; 23(2)$ 177-83.

[147] Napolitano GE. Fatty acids as trophic and chemical markers in freshwater ecosystems. In: Arts MT, Wainman BC, editors. Lipids in Freshwater Ecosystems. Verlag: Springer; 1999. p. 21-44.

[148] Parish CC. Determination of total lipid, lipid classes and fatty acids in aquatic samples In: Arts MT, Wainman BC, editors. Lipids in Freshwater Ecosystems. Verlag: Springer; 1999. p. 4-20.

[149] Dadd RH, Kleinjan JE, Stanley-Samuelson DW. Polyunsaturated fatty acids of mosquitoes reared with single dietary polyunsaturates. Insect Biochemistry. 1987; 17 7-16.

[150] Dadd RH, Kleinjan JE. Prostaglandin sparing of dietary arachidonic-acid in the mosquito Culex pipiens. Journal of Insect Physiology. 1988; 34(8) 779-85.

[151] Nor Aliza AR, Stanley DW. A digestive phospholipase A2 in larval mosquitoes, Aedes aegypti. Insect Biochemistry and Molecular Biology. 1998; 28 561-9.

[152] Timmermann SE, Briegel H. Effect of plant, fungal and animal diets on mosquito development. Entomologia Experimentalis Et Applicata. 1996; 80(1) 173-6.

[153] Kominkova D, Rejmankova E, Grieco J, Achee N. Fatty acids in anopheline mosquito and their habitats. Journal of Vector Ecology. 2012; 37(2) 382-395.

[154] Blaustein L, Kiflawi M, Eitam A, Mangel M, Cohen JE. Oviposition habitat selection in response to risk of predation in temporary pools: mode of detection and consistency across experimental venue. Oecologia. 2004; 138(2) 300-5.

[155] Kumar R, Muhid P, Dahms HU, Tseng LC, Hwang JS. Potential of three aquatic predators to control mosquitoes in the presence of alternative prey: a comparative experimental assessment. Marine and Freshwater Research. 2008; 59(9) 817-35. 
[156] Shaalan EAS, Canyon DV. Aquatic insect predators and mosquito control. Tropical Biomedicine. 2009; 26(3) 223-61.

[157] Kweka EJ. Predation efficiency of Anopheles gambiae larvae by aquatic predators in western Kenya highlands. Tropical Medicine \& International Health. 2012; 1753.

[158] Knight TM, Chase JM, Goss CW, Knight JJ. Effects of interspecific competition, predation, and their interaction on survival and development time of immature Anopheles quadrimaculatus. Journal of Vector Ecology. 2004; 29(2) 277-84.

[159] Juliano SA. Species interactions among larval mosquitoes: context dependence across habitat gradients. Annual Review of Entomology. 2009; 54 37-56.

[160] Gimonneau G, Pombi M, Dabire RK, Diabate A, Morand S, Simard F. Behavioural responses of Anopheles gambiae sensu stricto $\mathrm{M}$ and $\mathrm{S}$ molecular form larvae to an aquatic predator in Burkina Faso. Parasites \& Vectors. 2012; 556.

[161] Hinman EH. Predators of the Culicidae (mosquitoes). I. The predators of larvae and pupae, exclusive of fish. Journal of Tropical Medicine and Hygiene. 1934; 37 129-34.

[162] Blaustein L, Margalit J. Mosquito larvae (Culiseta-longiareolata) prey upon and compete with toad tadpoles (Bufo-viridis). Journal of Animal Ecology. 1994; 63(4) 841-50.

[163] Mokany A, Shine R. Biological warfare in the garden pond: tadpoles suppress the growth of mosquito larvae. Ecological Entomology. 2003; 28(1) 102-8.

[164] Grill CP, Juliano SA. Predicting species interactions based on behaviour: Predation and competition in container-dwelling mosquitoes. Journal of Animal Ecology. 1996; 65(1) 63-76.

[165] Blaustein L, Karban R. Indirect effects of the mosquitofish Gambusia-affinis on the mosquito Culex-tarsalis. Limnology and Oceanography. 1990; 35(3) 767-71.

[166] Mokany A. Impact of tadpoles and mosquito larvae on ephemeral pond structure and processes. Marine and Freshwater Research. 2007; 58(5) 436-44.

[167] Kumar R, Hwang JS. Larvicidal efficiency of aquatic predators: A perspective for mosquito biocontrol. Zoological Studies. 2006; 45(4) 447-66.

[168] Mogi M. Insects and other invertebrate predators. Journal of the American Mosquito Control Association. 2007; 23(2) 93-109.

[169] Quiroz-Martinez H, Rodriguez-Castro A. Aquatic insects as predators of mosquito larvae. Journal of the American Mosquito Control Association. 2007; 23(2) 110-7.

[170] Rozendaal JA. Vector Control: Methods for Use by Individuals and Communities. Geneva: World Health Organization; 1997.

[171] Chandra G, Bhattacharjee I, Chatterjee SN, Ghosh A. Mosquito control by larvivorous fish. Indian Journal of Medical Research. 2008; 127(1) 13-27. 
[172] Service MW. Identification of predators of Anopheles gambiae resting in huts, by precipitin test. Transactions of the Royal Society of Tropical Medicine and Hygiene. 1973; 67(1) 33-4.

[173] Service MW. Mortalities of immature stages of species-b of Anopheles gambiae complex in kenya - comparison between rice fields and temporary pools, identification of predators, and effects of insecticidal spraying. Journal of Medical Entomology. 1977; 13(4-5) 535-45.

[174] Caillouet KA, Keating J, Eisele TP. Characterization of aquatic mosquito habitat, natural enemies, and immature mosquitoes in the Artibonite Valley, Haiti. Journal of Vector Ecology. 2008; 33(1) 191-7.

[175] Louca V, Lucas MC, Green C, Majambere S, Fillinger U, Lindsay SW. Role of fish as predators of mosquito larvae on the floodplain of the Gambia River. Journal of Medical Entomology. 2009; 46(3) 546-56.

[176] Walton WE. Larvivorous fish including Gambusia. Journal of the American Mosquito Control Association. 2007; 23(2) 184-220.

[177] Preston DL, Henderson JS, Johnson PTJ. Community ecology of invasions: direct and indirect effects of multiple invasive species on aquatic communities. Ecology. 2012; 93(6) 1254-61.

[178] Bence JR. Indirect effects and biological-control of mosquitos by mosquitofish. Journal of Applied Ecology. 1988; 25(2) 505-21.

[179] Diabate A, Dabire RK, Heidenberger K, Crawford J, Lamp WO, Culler LE, et al. Evidence for divergent selection between the molecular forms of Anopheles gambiae: role of predation. BMC Evolutionary Biology. 2008; 85.

[180] Gimonneau G, Bouyer J, Morand S, Besansky NJ, Diabate A, Simard F. A behavioral mechanism underlying ecological divergence in the malaria mosquito Anopheles gambiae. Behavioral Ecology. 2010; 21(5) 1087-92.

[181] Morris DW. Toward an ecological synthesis: a case for habitat selection. Oecologia. $2003 ; 136(1) 1-13$.

[182] Impoinvil DE, Keating J, Mbogo CM, Potts MD, Chowdhury RR, Beier JC. Abundance of immature Anopheles and Culicines (Diptera : Culicidae) in different water body types in the urban environment of Malindi, Kenya. Journal of Vector Ecology. 2008; 33(1) 107-16.

[183] Munga S, Minakawa N, Zhou GF, Barrack OOJ, Githeko AK, Yan GY. Oviposition site preference and egg hatchability of Anopheles gambiae: Effects of land cover types. Journal of Medical Entomology. 2005; 42(6) 993-7.

[184] Keating J, MacIntyre K, Mbogo C, Githeko A, Regens JL, Swalm C, et al. A geographic sampling strategy for studying relationships between human activity and malaria 
vectors in urban Africa. American Journal of Tropical Medicine and Hygiene. 2003; 68(3) 357-65.

[185] Blaustein L. Oviposition site selection in response to risk of predation: evidence from aquatic habitats and consequences for population dynamics and community structure. In: Wasser SP, editor. Evolutionary theory and processes: modern perspectives. Dordrecht: Kluwer Academic Publishers; 1999. p. 441-56.

[186] Kershenbaum A, Spencer M, Blaustein L, Cohen JE. Modelling evolutionarily stable strategies in oviposition site selection, with varying risks of predation and intraspecific competition. Evolutionary Ecology. 2012; 26(4) 955-74.

[187] Warburg A, Faiman R, Shtern A, Silberbush A, Markman S, Cohen JE, et al. Oviposition habitat selection by Anopheles gambiae in response to chemical cues by Notonecta maculata. Journal of Vector Ecology. 2011; 36(2) 421-5.

[188] Vonesh JR, Blaustein L. Predator-induced shifts in mosquito oviposition site selection: A meta-analysis and implications for vector control. Israel Journal of Ecology \& Evolution. 2010; 56(3-4) 263-79.

[189] Beck LR, Lobitz BM, Wood BL. Remote sensing and human health: New sensors and new opportunities. Emerging Infectious Diseases. 2000; 6(3) 217-27.

[190] Stoops CA, Gionar YR, Shinta, Sismadi P, Rachmat A, Elyazar IF, et al. Remotelysensed land use patterns and the presence of Anopheles larvae (Diptera : Culicidae) in Sukabumi, West Java, Indonesia. Journal of Vector Ecology. 2008; 33(1) 30-9.

[191] Lourenco PM, Sousa CA, Seixas J, Lopes P, Novo MT, Almeida APG. Anopheles atroparvus density modeling using MODIS NDVI in a former malarious area in Portugal. Journal of Vector Ecology. 2011; 36(2) 279-91.

[192] Machault V, Vignolles C, Borchi F, Vounatsou P, Pages F, Briolant S, et al. The use of remotely sensed environmental data in the study of malaria. Geospatial Health. 2011; 5(2) 151-68.

[193] Dambach P, Machault V, Lacaux JP, Vignolles C, Sie A, Sauerborn R. Utilization of combined remote sensing techniques to detect environmental variables influencing malaria vector densities in rural West Africa. International Journal of Health Geographics. 2012; 11, 8.

[194] Turner W, Spector S, Gardiner N, Fladeland M, Sterling E, Steininger M. Remote sensing for biodiversity science and conservation. Trends in Ecology \& Evolution. 2003; 18(6) 306-14.

[195] Buermann W, Saatchi S, Smith TB, Zutta BR, Chaves JA, Mila B, et al. Predicting species distributions across the Amazonian and Andean regions using remote sensing data. Journal of Biogeography. 2008; 35(7) 1160-76.

[196] Rakotomanana F, Randremanana RV, Rabarijaona LP, Duchemin JB, Ratovonjato J, Ariey F, et al. Determining areas that require indoor insecticide spraying using Multi 
Criteria Evaluation, a decision-support tool for malaria vector control programmes in the Central Highlands of Madagascar. International Journal of Health Geographics. $2007 ; 6,2$.

[197] Rakotomanana F, Ratovonjato J, Randremanana RV, Randrianasolo L, Raherinjafy R, Rudant JP, et al. Geographical and environmental approaches to urban malaria in Antananarivo (Madagascar). BMC Infectious Diseases. 2010; 10, 173.

[198] Mushinzimana E, Munga S, Minakawa N, Li L, Feng CC, Bian L, et al. Landscape determinants and remote sensing of anopheline mosquito larval habitats in the western Kenya highlands. Malaria Journal. 2006; 5, 13.

[199] Jacob BG, Muturi EJ, Mwangangi JM, Funes J, Caamano EX, Muriu S, et al. Remote and field level quantification of vegetation covariates for malaria mapping in three rice agro-village complexes in Central Kenya. International Journal of Health Geographics. 2007; 621.

[200] Munga S, Yakob L, Mushinzimana E, Zhou GF, Ouna T, Minakawa N, et al. Land use and land cover changes and spatiotemporal dynamics of anopheline larval habitats during a four-year period in a highland community of Africa. American Journal of Tropical Medicine and Hygiene. 2009; 81(6) 1079-84.

[201] Mutuku FM, Bayoh MN, Hightower AW, Vulule JM, Gimnig JE, Mueke JM, et al. A supervised land cover classification of a western Kenya lowland endemic for human malaria: associations of land cover with larval Anopheles habitats. International Journal of Health Geographics. 2009; 8, 19.

[202] Clennon JA, Kamanga A, Musapa M, Shiff C, Glass GE. Identifying malaria vector breeding habitats with remote sensing data and terrain-based landscape indices in Zambia. International Journal of Health Geographics. 2010; 9, 58.

[203] Ahmad R, Ali WN, Nor ZM, Ismail Z, Hadi AA, Ibrahim MN, et al. Mapping of mosquito breeding sites in malaria endemic areas in Pos Lenjang, Kuala Lipis, Pahang, Malaysia. Malaria Journal. 2011; 10, 361.

[204] Achee NL, Grieco JP, Masuoka P, Andre RG, Roberts DR, Thomas J, et al. Use of remote sensing and geographic information systems to predict locations of Anopheles darlingi-positive breeding sites within the Sibun River in Belize, central America. Journal of Medical Entomology. 2006; 43(2) 382-92.

[205] Roberts DR, Paris JF, Manguin S, Harbach RE, Woodruff R, Rejmankova E, et al. Predictions of malaria vector distribution in Belize based on multispectral satellite data. American Journal of Tropical Medicine and Hygiene. 1996; 54(3) 304-8.

[206] Peterson AT. Biogeography of diseases: a framework for analysis. Naturwissenschaften. 2008; 95(6) 483-91.

[207] Peterson AT, Martinez-Campos C, Nakazawa Y, Martinez-Meyer E. Time-specific ecological niche modeling predicts spatial dynamics of vector insects and human 
dengue cases. Transactions of the Royal Society of Tropical Medicine and Hygiene. 2005; 99(9) 647-55.

[208] Levine RS, Peterson AT, Benedict MQ. Geographic and ecologic distributions of the Anopheles gambiae complex predicted using a genetic algorithm. American Journal of Tropical Medicine and Hygiene. 2004; 70(2) 105-9.

[209] Patz JA, Olson SH, Uejio CK, Gibbs HK. Disease emergence from global climate and land use change. Medical Clinics of North America. 2008; 92(6) 1473-91.

[210] Myers SS, Patz JA. Emerging threats to human health from global environmental change. Annual Review of Environment and Resources. 2009; 34 223-52.

[211] IPCC. Climate Change 2007: The Physical Science Basis. Contribution of Working Group I to the Fourth Assessment Report of the Intergovernmental Panel on Climate Change. Cambridge and New York 2007.

[212] McMichael AJ, Friel S, Nyong A, Corvalan C. Global environmental change and health: impacts, inequalities, and the health sector. British Medical Journal. 2008; 336(7637) 191-4.

[213] Carpenter SR, Stanley EH, Vander Zanden MJ. State of the world's freshwater ecosystems: Physical, chemical, and biological changes. Annual Review of Environment and Resources, Vol 36. 2011; 36 75-99.

[214] Tran A, Poncon N, Toty C, Linard C, Guis H, Ferre JB, et al. Using remote sensing to map larval and adult populations of Anopheles hyrcanus (Diptera: Culicidae) a potential malaria vector in Southern France. International Journal of Health Geographics. $2008 ; 7,9$.

[215] Martens P, Kovats RS, Nijhof S, de Vries P, Livermore MTJ, Bradley DJ, et al. Climate change and future populations at risk of malaria. Global Environmental Change-Human and Policy Dimensions. 1999; 9 S89-S107.

[216] Molyneux DH. Vectorborne parasitic diseases - an overview of recent changes. International Journal for Parasitology. 1998; 28(6) 927-34.

[217] Molyneux DH. Common themes in changing vector-borne disease scenarios. Transactions of the Royal Society of Tropical Medicine and Hygiene. 2003; 97(2) 129-32.

[218] Afrane YA, Githeko AK, Yan GY. The ecology of Anopheles mosquitoes under climate change: Case studies from the effects of deforestation in East African highlands. Year in Ecology and Conservation Biology. 2012; 1249 204-10.

[219] Berger F, Flamand C, Musset L, Djossou F, Rosine J, Sanquer MA, et al. Investigation of a sudden malaria outbreak in the isolated Amazonian village of Saul, French Guiana, January-April 2009. American Journal of Tropical Medicine and Hygiene. 2012; 86(4) 591-7. 
[220] Hackett LW. Distribution of Malaria. In: Boyd MF, editor. Malariology. Philadelphia: Saunders; 1949. p. 722-35.

[221] Fontenille D, Simard F. Unravelling complexities in human malaria transmission dynamics in Africa through a comprehensive knowledge of vector populations. Comparative Immunology Microbiology and Infectious Diseases. 2004; 27(5) 357-75.

[222] Gimonneau G, Pombi M, Choisy M, Morand S, Dabire RK, Simard F. Larval habitat segregation between the molecular forms of the mosquito Anopheles gambiae in a rice field area of Burkina Faso, West Africa. Medical and Veterinary Entomology. 2012; 26(1) 9-17.

[223] Laporta GZ, Ramos DG, Ribeiro MC, Sallum MAM. Habitat suitability of Anopheles vector species and association with human malaria in the Atlantic Forest in southeastern Brazil. Memorias Do Instituto Oswaldo Cruz. 2011; 106 239-49.

[224] Yasuoka J, Levins R. Impact of deforestation and agricultural development on anopheline ecology and malaria epidemiology. American Journal of Tropical Medicine and Hygiene. 2007; 76(3) 450-60.

[225] Vittor AY, Pan W, Gilman RH, Tielsch J, Glass G, Shields T, et al. Linking deforestation to malaria in the Amazon: Characterization of the breeding habitat of the principal malaria vector, Anopheles darlingi. American Journal of Tropical Medicine and Hygiene. 2009; 81(1) 5-12.

[226] Conn JE, Wilkerson RC, Segura MNO, De Souza RTL, Schlichting CD, Wirtz RA, et al. Emergence of a new neotropical malaria vector facilitated by human migration and changes in land use. American Journal of Tropical Medicine and Hygiene. 2002; 66(1) 18-22.

[227] Tadei WP, Thatcher BD, Santos JMH, Scarpassa VM, Rodrigues IB, Rafael MS. Ecologic observations on anopheline vectors of malaria in the Brazilian Amazon. American Journal of Tropical Medicine and Hygiene. 1998; 59(2) 325-35.

[228] Lerer LB, Scudder T. Health impacts of large dams. Environmental Impact Assessment Review. 1999; 19(2) 113-23.

[229] Jobin WR. Dams and Disease: Ecological Design and Health Impacts of Large Dams, Canals and Irrigation Systems. London: Routledge; 1999.

[230] Hunter JM. Inherited burden of disease: agricultural dams and the persistence of bloody urine (Schistosomiasis hematobium) in the Upper East Region of Ghana, 1959-1997. Social Science \& Medicine. 2003; 56(2) 219-34.

[231] Keiser J, De Castro MC, Maltese MF, Bos R, Tanner M, Singer BH, et al. Effect of irrigation and large dams on the burden of malaria on a global and regional scale. American Journal of Tropical Medicine and Hygiene. 2005; 72(4) 392-406. 
[232] Kibret S, Lautze J, Boelee E, McCartney M. How does an Ethiopian dam increase malaria? Entomological determinants around the Koka reservoir. Tropical Medicine \& International Health. 2012; 17(11), 1320-8.

[233] Zeilhofer P, dos Santos ES, Ribeiro ALM, Miyazaki RD, dos Santos MA. Habitat suitability mapping of Anopheles darlingi in the surroundings of the Manso hydropower plant reservoir, Mato Grosso, Central Brazil. International Journal of Health Geographics. 2007; 6, 7 .

[234] Willott E. Restoring nature, without mosquitoes? Restoration Ecology. 2004; 12(2) $147-53$

[235] Goma LKH. The influence of man's activities on swamp-mosquito breeding in Uganda (Diptera: Culicidae). Journal of the Entomological Society of South Africa. 1961; 24 231-47.

[236] Malan HL, Appleton CC, Day JA, Dini J. Wetlands and invertebrate disease hosts: Are we asking for trouble? Water Sa. 2009; 35(5) 753-67.

[237] Carlson JC, Byrd BD, Omlin FX. Field assessments in western Kenya link malaria vectors to environmentally disturbed habitats during the dry season. BMC Public Health. 2004; 4, 33.

[238] Thullen JS, Sartoris JJ, Walton WE. Effects of vegetation management in constructed wetland treatment cells on water quality and mosquito production. Ecological Engineering. 2002; 18(4) 441-57.

[239] Walton WE, Popko DA, Van Dam AR, Merrill A, Lythgoe J, Hess B. Width of planting beds for emergent vegetation influences mosquito production from a constructed wetland in California (USA). Ecological Engineering. 2012; 42 150-9.

[240] Knight RL, Walton WE, O'Meara GF, Reisen WK, Wass R. Strategies for effective mosquito control in constructed treatment wetlands. Ecological Engineering. 2003; 21(4-5) 211-32.

[241] Sanford MR, Chan K, Walton WE. Effects of inorganic nitrogen enrichment on mosquitoes (Diptera : Culicidae) and the associated aquatic community in constructed treatment wetlands. Journal of Medical Entomology. 2005; 42(5) 766-76.

[242] Yadav P, Foster WA, Mitsch WJ, Grewal PS. Factors affecting mosquito populations in created wetlands in urban landscapes. Urban Ecosystems. 2012; 15(2) 499-511.

[243] Greenway M. The role of constructed wetlands in secondary effluent treatment and water reuse in subtropical and arid Australia. Ecological Engineering. 2005; 25(5) 501-9.

[244] Carlson DB, Knight RL. Mosquito production and hydrological capacity of southeast Florida impoundments used for waste-water retention. Journal of the American Mosquito Control Association. 1987; 3(1) 74-83. 
[245] Vitousek PM, Aber JD, Howarth RW, Likens GE, Matson PA, Schindler DW, et al. Human alteration of the global nitrogen cycle: Sources and consequences. Ecological Applications. 1997; 7(3) 737-50.

[246] Carpenter SR, Caraco NF, Correll DL, Howarth RW, Sharpley AN, Smith VH. Nonpoint pollution of surface waters with phosphorus and nitrogen. Ecological Applications. 1998; 8(3) 559-68.

[247] Howarth RW, Anderson D, Cloern J, Elfring C, Hopkinson C, Lapointe B, et al. Nutrient pollution of coastal rivers, bays, and seas. Issues in Ecology. 2000; 7 1-15.

[248] Galloway JN, Cowling EB. Reactive nitrogen and the world: 200 years of change. Ambio. 2002; 31(2) 64-71.

[249] Camargo JA, Alonso A. Ecological and toxicological effects of inorganic nitrogen pollution in aquatic ecosystems: A global assessment. Environment International. 2006; 32(6) 831-49.

[250] Townsend AR, Howarth RW, Bazzaz FA, Booth MS, Cleveland CC, Collinge SK, et al. Human health effects of a changing global nitrogen cycle. Frontiers in Ecology and the Environment. 2003; 1(5) 240-6.

[251] Teng HJ, Wu YL, Wang SJ, Lin C. Effects of environmental factors on abundance of Anopheles minimus (Diptera : Culicidae) larvae and their seasonal fluctuation in Taiwan. Environmental Entomology. 1998; 27(2) 324-8.

[252] Minakawa N, Dida GO, Sonye GO, Futami K, Njenga SM. Malaria vectors in Lake Victoria and adjacent habitats in western Kenya. Plos One. 2012; 7(3) e32725.

[253] Patz JA, Olson SH. Malaria risk and temperature: Influences from global climate change and local land use practices. Proceedings of the National Academy of Sciences of the United States of America. 2006; 103(15) 5635-6.

[254] Reiter P, Thomas CJ, Atkinson PM, Hay SI, Randolph SE, Rogers DJ, et al. Global warming and malaria: a call for accuracy. Lancet Infectious Diseases. 2004; 4(6) 323-4.

[255] Chaves LF, Koenraadt CJM. Climate change and highland malaria: Fresh air for a hot debate. Quarterly Review of Biology. 2010; 85(1) 27-55.

[256] Pascual M, Ahumada JA, Chaves LF, Rodo X, Bouma M. Malaria resurgence in the East African highlands: Temperature trends revisited. Proceedings of the National Academy of Sciences of the United States of America. 2006; 103(15) 5829-34.

[257] Chaves LF, Hashizume M, Satake A, Minakawa N. Regime shifts and heterogeneous trends in malaria time series from Western Kenya Highlands. Parasitology. 2012; 139(1) 14-25.

[258] Bomblies A. Modeling the role of rainfall patterns in seasonal malaria transmission. Climatic Change. 2012; 112(3-4) 673-85. 
[259] Trung HD, Van Bortel W, Sochantha T, Keokenchanh K, Quang NT, Cong LD, et al. Malaria transmission and major malaria vectors in different geographical areas of Southeast Asia. Tropical Medicine \& International Health. 2004; 9(2) 230-7.

[260] Gunasekaran K, Jambulingam P, Srinivasan R, Sadanandane C, Doss PSB, Sabesan S, et al. Malaria receptivity in the tsunami-hit coastal villages of southern India. Lancet Infectious Diseases. 2005; 5(9) 531-2.

[261] Jude PJ, Dharshini S, Vinobaba M, Surendran SN, Ramasamy R. Anopheles culicifacies breeding in brackish waters in Sri Lanka and implications for malaria control. Malaria Journal. 2010; 9, 106.

[262] Reinbold-Wasson DD, Sardelis MR, Jones JW, Watts DM, Fernandez R, Carbajal F, et al. Determinants of Anopheles seasonal distribution patterns across a forest to periurban gradient near Iquitos, Peru. American Journal of Tropical Medicine and Hygiene. 2012; 86(3) 459-63.

[263] Charlwood JD. Biological variation in Anopheles darlingi root. Memorias Do Instituto Oswaldo Cruz. 1996; 91(4) 391-8.

[264] Keiser J, Singer BH, Utzinger J. Reducing the burden of malaria in different eco-epidemiological settings with environmental management: a systematic review. Lancet Infectious Diseases. 2005; 5(11) 695-708.

[265] Lambrechts L, Knox TB, Wong J, Liebman KA, Albright RG, Stoddard ST. Shifting priorities in vector biology to improve control of vector-borne disease. Tropical Medicine \& International Health. 2009; 14(12) 1505-14.

[266] Raghavendra K, Barik TK, Reddy BPN, Sharma P, Dash AP. Malaria vector control: from past to future. Parasitology Research. 2011; 108(4) 757-79.

[267] Najera JA, Gonzalez-Silva M, Alonso PL. Some lessons for the future from the Global Malaria Eradication Programme (1955-1969). Plos Medicine. 2011; 8(1) e1000412.

[268] Worrall E, Fillinger U. Large-scale use of mosquito larval source management for malaria control in Africa: A cost analysis. Malaria Journal. 2011; 10338.

[269] McKenzie FE, Baird JK, Beier JC, Lal AA, Bossert WH. A biologic basis for integrated malaria control. American Journal of Tropical Medicine and Hygiene. 2002; 67(6) 571-7.

[270] Gu WD, Novak RJ. Habitat-based modeling of impacts of mosquito larval interventions on entomological inoculation rates, incidence, and prevalence of malaria. American Journal of Tropical Medicine and Hygiene. 2005; 73(3) 546-52.

[271] Fillinger U, Lindsay SW. Larval source management for malaria control in Africa: myths and reality. Malaria Journal. 2011; 10353. 
[272] Minakawa N, Mutero CM, Githure JI, Beier JC, Yan GY. Spatial distribution and habitat characterization of anopheline mosquito larvae in western Kenya. American Journal of Tropical Medicine and Hygiene. 1999; 61(6) 1010-6.

[273] Abdul-Ghani R, Al-Mekhlafi AM, Alabsi MS. Microbial control of malaria: Biological warfare against the parasite and its vector. Acta Tropica. 2012; 121(2) 71-84.

[274] Mittal PK. Biolarvicides in vector control: challenges and prospects. Journal of Vector Borne Diseases. 2003; 40 20-32.

[275] Favia G, Ricci I, Damiani C, Raddadi N, Crotti E, Marzorati M, et al. Bacteria of the genus Asaia stably associate with Anopheles stephensi, an Asian malarial mosquito vector. Proceedings of the National Academy of Sciences of the United States of America. 2007; 104(21) 9047-51.

[276] Cirimotich CM, Ramirez JL, Dimopoulos G. Native microbiota shape insect vector competence for human pathogens. Cell Host \& Microbe. 2011; 10(4) 307-10.

[277] Chouaia B, Rossi P, Epis S, Mosca M, Ricci I, Damiani C, et al. Delayed larval development in Anopheles mosquitoes deprived of Asaia bacterial symbionts. BMC Microbiology. 2012; 12, suppl. 1, S2.

[278] Rani A, Sharma A, Rajagopal R, Adak T, Bhatnagar RK. Bacterial diversity analysis of larvae and adult midgut microflora using culture-dependent and culture-independent methods in lab-reared and field-collected Anopheles stephensi-an Asian malarial vector. BMC Microbiology. 2009; 9, 96.

[279] Peterson AT. Shifting suitability for malaria vectors across Africa with warming climates. BMC Infectious Diseases. 2009; 9, 59. 